\title{
An Empirical Analysis of Capacity Costs*
}

by

\author{
Merle Ederhof \\ Stanford University
}

\author{
Venky Nagar \\ University of Michigan
}

\author{
Madhav Rajan \\ Stanford University
}

\begin{abstract}
CES 17-26
March, 2017

The research program of the Center for Economic Studies (CES) produces a wide range of economic analyses to improve the statistical programs of the U.S. Census Bureau. Many of these analyses take the form of CES research papers. The papers have not undergone the review accorded Census Bureau publications and no endorsement should be inferred. Any opinions and conclusions expressed herein are those of the author(s) and do not necessarily represent the views of the U.S. Census Bureau. All results have been reviewed to ensure that no confidential information is disclosed. Republication in whole or part must be cleared with the authors.

To obtain information about the series, see www.census.gov/ces or contact J. David Brown, Editor, Discussion Papers, U.S. Census Bureau, Center for Economic Studies 5K034A, 4600 Silver Hill Road, Washington, DC 20233, CES.Working.Papers@census.gov. To subscribe to the series, please click here.
\end{abstract}




\begin{abstract}
A central premise of management accounting is that including the cost of unused capacity in product costs can distort these costs and misguide users. Yet, there is little large-scale empirical evidence on the materiality of the cost of unused capacity. This study uses a confidential Census sample of 151,900 U.S. manufacturing plants from 1974-2011 to investigate the impact of separating the cost of unused capacity. We find that excluding the cost of unused capacity increases operating profit margins by approximately 26 percent. This order of magnitude is economically significant, and is pervasive across industries and over time. In additional analyses, we find that separating the cost of unused capacity largely smooths the time-series variation in unitized product costs and profit margins. Our finding of higher mean and lower variation of adjusted margins should be of considerable interest to both investors and managers.
\end{abstract}

\footnotetext{
*Any opinions and conclusions expressed herein are those of the authors, and do not necessarily represent the views of the U.S. Census Bureau. All results have been reviewed by the Census to ensure that no confidential information is disclosed. We thank the staff at Michigan and Stanford RDC, and seminar participants at Duke University.
} 


\section{INTRODUCTION}

Capacity costing is a central concept in managerial accounting. Managerial accounting textbooks and numerous case studies argue that including the cost of unused capacity in product costs can significantly inflate true product costs and understate true profit measures, in turn. ${ }^{1}$ Cost measures that are not adjusted for the level of capacity utilization may mask the costs' true source, and mislead users of the cost information. For example, investors and management may erroneously focus on improving product design or production efficiency instead of confronting unused capacity. The importance of capacity is also evident in financial disclosures, where capacity is often viewed as a risk factor, and sometimes management will disclose unused capacity figures explicitly (see our Exhibit 1). This study is an attempt to systematically estimate the materiality of unused capacity on the measurement of product costs and margins in the US economy. ${ }^{2}$

The extent to which including the cost of unused capacity will systematically inflate product costs and understate profit measures depends on the level of unused capacity in the constellation of US firms, and is therefore an empirical issue. Yet, existing empirical evidence addressing this question is quite limited. Prior research includes individual case studies, as well as some small-sample studies at the plant level (see Appendix A). ${ }^{3}$ Measuring the cost of unused

\footnotetext{
${ }^{1}$ Horngren et al., 2015, chapter 9; Kaplan and Atkinson, 1998, chapters 1 and 9; Cooper and Kaplan, 1991, chapter 3; Cooper and Kaplan, 1988, 1992; Kaplan, 1994. Relevant HBS case studies include: 'Bridgeton Industries'; 'Micro Devices Division'; 'Schulze Waxed Containers'; 'Hewlett Packard: Queensferry Telecommunications Division'; 'Anagene, Inc.'.

${ }^{2}$ Financial reporting standard SFAS 151 requires that items such as idle facility expense, excessive spoilage, double freight, and rehandling costs be recognized as period expense. Our study does not directly relate to SFAS 151 in that we do not explicitly examine each of the SFAS 151 items. Rather, our study explores the deeper question behind these items, namely whether accounting for unused capacity can make a material difference to product costs and margins (Bettinghaus et al. 2012).

${ }^{3}$ Individual case and small-sample studies include Anderson (1995), Banker et al. (1995), Bruggen et al. (2011), and Foster and Gupta (1990). Banker et al. (1988) use industry-level, not plant-level, data to examine optimal capacity levels. Large-sample studies are interested in other research questions such as disclosure and segment reporting (e.g., Bens et al. 2011), or the impact of strength of employment protection legislation on level of cost stickiness
} 
capacity using firm-level data from Compustat is rather challenging since the reported financial data are usually too aggregate. The few studies that use data from Compustat take a fairly indirect approach. ${ }^{4}$

In this study, we directly estimate the impact of excluding the cost of unused capacity on product costs and profit margins using a comprehensive sample of U.S. manufacturing plants. We exploit the fact that the Census surveys plants (referred to as 'establishments' by the Census) regularly and collects considerable data on their operational activities. Researchers can obtain this data from the Census under strict confidentiality guidelines, and can release their findings to the public following Census approval.

We analyze a sample of 151,900 U.S. manufacturing plants from 1974-2011 in industries ranging from 'Industrial Machinery \& Equipment' to 'Lumber \& Wood Products' and 'Food \& Kindred Products'. We develop detailed estimates of the cost of unused capacity and analyze the impact of separating these costs on product costs and profit margins. We find that excluding the cost of unused capacity increases operating profit margins by $26 \%$, on average. This number is economically significant from the perspective of managerial decision-making and also considering the high sensitivity of stock prices to profit measures (e.g., Bradshaw and Sloan 2002). This increase in profit margins reflects a decrease in product costs of, on average, $6 \%$ when the cost of unused capacity is excluded. These findings are pervasive across industries and over time. ${ }^{5}$

(Banker at al. 2013), or the effect of zero-earnings benchmark on the level of cost stickiness (e.g., Dierynck et al. 2012).

${ }^{4}$ E.g., Young et al. 2014 test if firms increased production levels after the passage of SFAS 151 (in order to increase capacity utilization and avoid expensing the cost of unused capacity in the current period).

${ }^{5}$ We do not compute p-values because removing unused capacity costs (weakly) decreases costs and improves margins with probability one. 
Having documented the mean effect of unused capacity on reported costs and margins, we then analyze the impact of separating the cost of unused capacity on the time-series variation of unitized product costs and profit margins. For the entire sample and for the majority of the industries we find that excluding the cost of unused capacity smooths the time-series of unitized product costs and profit margins. This result should be of great interest to managers and investors, who typically wish to see a profit margin figure that is not just high but also steady over time (e.g., Burghstahler and Dichev 1997).

Section 2 develops the hypotheses. Section 3 discusses the sample and the measures. Section 4 conducts the main analyses, and Section 5 concludes.

\section{DEVELOPMENT OF HYPOTHESES}

A basic arithmetic principle in management accounting is that removing the cost of unused capacity reduces product costs and increases profit margins (Horngren et al., 2009, Ch.15), but it is an open empirical question whether the impacts are material. Our first hypothesis is:

H1: Excluding the cost of unused capacity materially reduces product costs and materially increases profit margins.

In addition to the above mean effect, excluding unused capacity costs also has an effect on the second-moment or the time-series variation of product costs. For example, Exhibit 1 discusses risks associated with capacity, one aspect of which is how capacity impacts the time series variation in product costs. As an illustration, consider a company with constant fixed 
capacity $\mathrm{C}$ that supports a practical production volume of 100 units. Assume further that the variable cost per unit is $\mathrm{V}$ and the actual production volume is $\mathrm{N}$. If only used capacity costs are allocated, each product's unit cost is the constant $\mathrm{V}+\mathrm{C} / 100$ irrespective of the production volume. On the other hand, if all of the capacity is allocated, the unit cost is $\mathrm{V}+\mathrm{C} / \mathrm{N}$, which varies with N. In this case, excluding excess capacity leads to a smoother time-series of unit product costs. $^{6}$

The above argument assumes that $\mathrm{V}$ is a given constant, and only $\mathrm{N}$ varies over time. The reality is that $\mathrm{V}$ could vary over time as well, and could be correlated with N. For example, there could be economies of scale that reduce $\mathrm{V}$ when $\mathrm{N}$ increases, or there could be congestion that increases $\mathrm{V}$ when $\mathrm{N}$ increases. Likewise, macro-demand and technological shocks could hit both $\mathrm{N}$ and $\mathrm{V}$, inducing further positive or negative correlations. In that case (Var is the variance):

$$
\operatorname{Var}(\mathrm{V}+\mathrm{C} / 100)=\operatorname{Var}(\mathrm{V})
$$

whereas:

$$
\operatorname{Var}(\mathrm{V}+\mathrm{C} / \mathrm{N})=\operatorname{Var}(\mathrm{V})+\mathrm{C}^{2} \operatorname{Var}(1 / \mathrm{N})+2 \mathrm{C} \cdot \operatorname{Covar}(\mathrm{V}, 1 / \mathrm{N})
$$

which could be higher or lower than $\operatorname{Var}(\mathrm{V})$ depending on the empirical nature of the sign and the magnitude of the covariance. ${ }^{7}$

We empirically explore this question in our second hypothesis (stated in the null form):

\footnotetext{
${ }^{6}$ This is the message of the HBS case 'Anagene, Inc.' where excess capacity induces excess volatility in reported product margins.

${ }^{7}$ The capacity $\mathrm{C}$ is fixed in the short run but can vary in the long run. Incorporating this additional source of (potentially correlated) variation can further increase or reduce the variance of $(\mathrm{V}+\mathrm{C} / \mathrm{N})$ relative to $(\mathrm{V}+\mathrm{C} / 100)$.
} 
H2: Excluding the cost of unused capacity does not impact the time series variation of unitized product costs and profit margins.

\section{SAMPLE AND MEASURES}

\subsection{Data Collection and Reporting Process}

The U.S. Census expends considerable resources to collect high quality data from plants, and relies on scholars at universities and the Fed and other governmental institutions to analyze the collected data. Firms respond to the Census surveys both due to social norms in the U.S., and because the Census guarantees confidentiality. ${ }^{8}$ In addition, the Census aggregates these surveys and issues reports at the economy-wide and the industry level, which can be extremely useful to firms in their planning process. In general, the Census data are considered to be comprehensive and high quality and are used extensively in the economics literature (see http://www.census.gov/research/).

We submitted a proposal to the Census Bureau, and upon its approval (a multiple-round process whose duration and outcome is partly dictated both by the proposal's purposefulness to the research mission of the Census and by the political climate and budgets and delays in Washington, D.C.), we went through FBI personnel checks and were granted access to the data in a secure facility (the data must be handled only in these secure premises: see http://www.census.gov/about/adrm/fsrdc/locations.html). Unlike CRSP and Compustat, which are widely available, the details of these databases cannot be properly explored until one gains Census access. As a result, understanding, collating, and matching these databases can be an

\footnotetext{
${ }^{8}$ Some firms will actually let Census survey workers access their internal ERP systems (personal communication).
} 
extremely cumbersome process (in addition to the initial difficulties in obtaining Census approval).

The Census further requires that all results be vetted by it, a process that can take several rounds. The Census wants to ensure that the results fall under the analyses previously approved in the proposal process. Moreover, the Census wants to make sure that the results meet its research mission without inadvertently violating confidentiality of the survey respondents. Consequently, several standard statistical estimates such as medians and histograms that can potentially report the value of a particular plant are disallowed, a constraint that is not present with "free" databases such as CRSP and Compustat. All the results presented in this study have been approved by the Census for public dissemination.

\subsection{Sample}

Our sample is comprised of U.S. manufacturing plants (or 'establishments') that are included in databases maintained by the Center for Economic Studies at the Bureau of the Census. Specially, we construct our sample by taking the year-by-year intersection of the Longitudinal Research Database (LRD) and the survey capturing capacity utilization (PCU). A firm may report multiple plants in the databases; the data are thus at the plant-level, not the firmlevel.

The LRD contains annual data on U.S. manufacturing plants (or establishments) that are collected via the Census of Manufactures (CM) and the Annual Survey of Manufactures (ASM). The CM collects data from the universe of manufacturing establishments; starting in 1967 it has been conducted every five years $(1963,1967,1972,1977,1982,1987,1992,1997,2002,2007$, 
2012). ${ }^{9}$ The Census conducts the ASM in every non-CM year (1973-1976, 1978-1981, 19831986, 1988-1991, 1993-1996, 1998-2001, 2003-2006, 2008-2011, 2013) and collects data from a subsample of the establishments with larger establishments being over-represented. ${ }^{10}$ The LRD contains roughly 300,000 - 400,000 establishments in CM years and roughly 50,000 - 70,000 establishments in non-CM years. The LRD includes information on industry, geography, outputs and inputs, and has been used in several studies (see Bens et al., 2011; Foster et al., 2006; Foster et al., 2014; Foster et al., 2016; Puri and Zarutskie, 2012). ${ }^{11}$

The Census initiated the plant capacity utilization survey in 1974. Through 2006, the survey was conducted annually (Plant Capacity Utilization Survey, PCU). Starting in 2007, the Census replaced the PCU by the Quarterly Survey of Plant Capacity Utilization (QPC), which, as the name indicates, is done on a quarterly basis. ${ }^{12}$

We annualize the QPC survey (by adding up the four quarters each year) and then merge the LRD with the plant capacity utilization survey. To be included in our sample, all variables required for the analyses have to be non-missing. Our final sample spans the years $1974-2011$ and includes 151,900 establishment-years. ${ }^{13}$

To summarize, all our analyses are done at the annual establishment level. We also convert all dollar figures to 1982 USD using the annual Producer Price Index for all commodities obtained from the Bureau of Labor Statistics. See Appendix B for detailed variable definitions.

\footnotetext{
${ }^{9}$ For very small establishments (less than five employees), data is imputed from administrative data.

${ }^{10}$ Broadly speaking, establishments with at least 250 employees are always included. Establishments of medium size are sampled with probabilities that increase in plant size, and small establishments are excluded from the sample.

${ }^{11}$ See Davis et al. (1996) and McGuckin and Pascoe (1988) for further details on the construction and content of the LRD.

${ }^{12}$ See bhs.econ.census.gov/bhs/pcu/ for a comprehensive description of the survey.

${ }^{13}$ The disclosure rules of the U.S. Census Bureau stipulate that all numbers be rounded to, at least, the nearest hundred.
} 
Table 1 shows the distribution of our sample across the years. Years 1986, 1988-1991, 1993-1996, 1998-2001, and 2003-2006 are not represented in our final sample since the data on 'depreciation charges' and 'rental payments' are not collected in the ASM in these years. A pattern that is immediately apparent is the substantially larger number of observations in the years 1997 and 2002. Inspection of the data reveals that it is driven by the variation in the number of establishments included in the capacity utilization survey. We are unable to ascertain the true cause of this variation. We control for this feature of the sample by presenting results year by year.

Table 2 shows the distribution of the sample across the ten industries within the manufacturing sector with the largest number of observations. The industries, which represent $73 \%$ of the entire sample, range from '35 - Industrial Machinery \& Equipment' to '20 - Food \& Kindred Products', '23 - Apparel \& Other Textile Products', and '36 - Electronic \& Other Electric Equipment'. Our sample thus appears to be comprehensively suited for our research question.

Graphs 1a and $1 \mathrm{~b}$ provide information on the size of the establishments in our sample. Graph 1a shows the kernel plot of the $\log$ of the total value of shipments. ${ }^{14}$ The kernel plot reflects the distribution of the log-transformed inflation-adjusted total value of shipments of our sample. The distribution peaks at approximately 10.26, reflecting an inflation-adjusted total value of shipments of $\$ 28.6$ million USD. The $5^{\text {th }}$ and $95^{\text {th }}$ percentile of the log-transformed distribution are 6.74 and 13.07 , reflecting inflation-adjusted total value of shipments of $\$ 845,600$ and $\$ 474.5$ million USD. The variation in the establishment sizes suggests yet again that the sample is comprehensively suited for our purposes.

\footnotetext{
${ }^{14}$ The disclosure rules of the U.S. Census Bureau require that a kernel plot be used instead of a histogram, and that the top and bottom 5\% be suppressed. We used the 'kdensity' command in STATA, which produces a kernel density estimate using the Epanechnikov kernel function (the default), using a bandwidth of 0.5.
} 
Graph $1 \mathrm{~b}$ shows a line plot of the annual cross-sectional means of the total value of shipments (converted to 1982 USD) for the 21 years that are represented in the sample (see Table 1). The means more or less grow over time except for the large drops in the years 1992, 1997, and 2002. Inspection of the entire population of establishments included in the CM and ASM reveals that the pattern observed in Graph $1 \mathrm{~b}$ is driven by the sampling process of the PCU/ QPC. As discussed above, this is also the source of the variation in the number of observations in our sample across the years in Table 1 . Graph $1 \mathrm{~b}$ and Table 1 indicate that there is a negative relationship between the number of establishments that are included in the capacity utilization survey and the average establishment size. The observed pattern is consistent with the notion that the additional establishments that are included in years 1992, 1997, and 2002 tend to be smaller and that the establishments that remain in the sample in years 2007-2011 tend to be larger. To ensure that this feature of the sample is not driving our results, we present all our results year by year.

\subsection{Measures}

\subsubsection{Capacity Utilization}

We create a measure of capacity utilization using two items that are reported in the PCU/ QPC survey. Specifically, we calculate the ratio of the value of actual production to the value of production at 'practical' (or 'full') capacity utilization. ${ }^{15}$

Graph 2a shows the distribution of capacity utilization for the entire sample, aggregated over all industries within the manufacturing sector and years. The mean capacity utilization is

\footnotetext{
15 'Practical (or 'full') capacity utilization' is the maximum level of utilization that can be sustained with a) the machinery and equipment that are in place and ready to operate, b) the normal downtime and shift schedule, and c) the current product mix.
} 
$73 \%$ and around $11.5 \%$ of the sample operate close to or at full capacity. $15 \%$ of the sample operate at or below $50 \%$ of capacity.

In order to shed some light on how capacity utilization varies across the industries within the manufacturing sector, Graph $2 \mathrm{~b}$ shows the individual distributions for each of the 10 largest industries in our sample that are listed in Table 2. The means of the distributions range from 0.65 for '37 - Transportation Equipment' to 0.78 for ' 23 - Apparel \& Other Textile Products'. We do not report the medians, in accordance with Census rules. Industries with higher capacity utilization means are also characterized by higher percentages of establishments that operate close to or at full capacity, with the numbers ranging from $7 \%$ for ' 36 - Electronic \& Other Electric Equipment' to $15 \%$ for '23 - Apparel \& Other Textile Products' and '24 Lumber \& Wood Products'. While there is variation in capacity utilization across the industries, none of them seem to be clear outliers. ${ }^{16}$

Graph 3 depicts the average capacity utilization over time. Graph 3a shows the annual cross-sectional means of capacity utilization for the entire sample. The means range from 0.62 in 2009 to 0.79 in 1992 . Capacity utilization dips in the downturn years of the early 1980 s, the stock market crash years of the early 2000s, and the years 2008-2009, which included the financial crisis and great recession. Note that all years are not present in the data (see Table 1).

Graph $3 \mathrm{~b}$ shows the annual cross-sectional means of capacity utilization for the 10 industries. As can be observed, most of the industries experienced the downturns and resulting decreases in capacity utilization in 1982 , 2002, and 2009. An exception is ' 20 - Food \& Kindred Products', whose capacity utilization has largely remained flat over the time period 1974 - 2011.

\footnotetext{
${ }^{16}$ Note that the Census does not permit reporting of bins with few observations. Thus, in Graph $2 b$, capacity utilization below 0.2 is included in the bins starting at 0.2 .
} 
Unsurprisingly, capacity utilization in ' 32 - Stone, Clay, \& Glass Products' and '24 - Lumber and Wood Products' decreased sharply during the housing-related great recession of 2009.

\subsubsection{Resource Costs}

The LRD contains information on the production costs incurred by the establishments. The cost items fall into three categories: Labor, material, and depreciation. In the labor category, the following cost components are reported: 'Production workers' wages', 'All other salaries and wages', and 'Total employer's cost for fringe benefits (supplemental labor costs)'. The individual material components that are broken out in the survey are 'Cost of materials, parts, components, containers, etc., used', 'Cost of products bought and sold as such', 'Cost of fuels', 'Cost of purchased electricity', and 'Cost of contract work done for you by others'. Depreciation costs include 'Total depreciation charges for the year' and 'Total rental payments'.

Capital expenditures for buildings and machinery during the year are reported in the survey; however, they are not included in our cost measures since the annual cost for buildings and machinery is captured by the depreciation costs. In the more recent years, the survey includes questions on the costs of some categories of purchased services such as advertising and communication services. We do not include these survey items in our cost measures for both conceptual and pragmatic reasons. Conceptually, the costs for the purchased services are all incurred at the corporate level and not the plant level. Thus, any reported costs would be the outcome of internal cost accounting systems, which are hard to compare across organizations. On a pragmatic level, none of the costs for the purchased services are reported by more than $5 \%$ of the survey respondents in any of the years. 
Graphs $4 \mathrm{a}$ and $4 \mathrm{~b}$ show the proportions of the three cost categories, labor, material, and depreciation, over time. Graph $4 \mathrm{a}$ shows the annual cross-sectional means of the three cost proportions for the entire sample. On average, labor costs make up one third of the total costs; the annual means range from $40 \%$ in 1974 to $26 \%$ in 2010 . The decreasing labor share is consistent with both the competitive pressures of labor outsourcing and technological advancement explanations.

At an average of $63 \%$, material costs constitute the largest cost category; the means range from $57 \%$ in 2002 to $69 \%$ in 2010 . One potential reason for this high proportion is that materials could be value-added, i.e., foreign or other plants may have already worked on the material considerably, raising its cost. Depreciation is the smallest category, making up $4 \%$ of total cost on average; the annual means range from $1 \%$ in 1976 to $6 \%$ in 2002.

Inspection of the entire population of establishments included in the CM and ASM reveals that the temporal variation in the cost proportions is influenced by the composition of our sample (recall from Table 1 and Graph 1 that average establishment size in our sample varies by year). Specifically, Graph $4 \mathrm{~b}$ shows that the proportion of material costs is increasing in establishment size, while labor and depreciation costs are decreasing is size. These observations are consistent with the notion that labor and depreciation costs have fixed components that afford economies of scale, while material costs are more variable in nature.

Graph 4c shows the annual cross-sectional means of the three cost proportions for the 10 industries. With the exception of industry '23 - Apparel \& Other Textile Products' in the 1970s, material is the largest, labor is the second largest, and depreciation is the smallest cost category in all of the industries and years. Averaging across all years, depreciation costs make up between $3 \%$ and $6 \%$ in all of the industries. The remaining material and labor cost categories are split 
most evenly in industry '23 - Apparel \& Other Textile Products' (material cost proportion is $53 \%$; labor cost proportion is $44 \%$ ) and most tilted towards material costs in industry '20 - Food \& Kindred Products' (material cost proportion is 78\%; labor cost proportion is 19\%). This industry has historically hired cheap migrant labor.

Interestingly, industries '35 - Industrial Machinery \& Equipment', '34 - Fabricated Metal Products', and '33 - Primary Metal Industries' show a remarkable drop-off in labor costs starting in the early 2000s, consistent with technological advances and the competitive force of extensive labor outsourcing in these industries. In addition, foreign plants could have extensively worked on the material shipped to US plants, raising its relative value added and its relative share of total costs. The declining labor share and the rising material cost share should not be surprising to any political observer who watched the 'Rust belt blue wall' states flip over to Donald Trump in the 2016 election. ${ }^{17}$

Finally, in Appendix A, we compare the magnitudes of our cost ratios to prior studies, and show that we are commensurable with them. This further serves to validate the quality of our data.

\section{ANALYSES AND FINDINGS}

\subsection{Measuring the Cost of Unused Capacity}

Our hypotheses concern the impact of allocating the cost of unused capacity onto product costs. We measure the cost of unused capacity as follows:

(1) Cost of unused capacity $\mathrm{pt}=(1-$ Capacity Utilization $\mathrm{pt}) *$ Fixed $_{\text {Cost }} \mathrm{pt}(\mathrm{p}=$ plant, $\mathrm{t}=$ year $)$

\footnotetext{
${ }^{17} \mathrm{http}: / /$ michaelmoore.com/trumpwillwin/
} 
While we can directly measure capacity utilization using the PCU/ QPC surveys, we have to estimate what portion of the resource costs discussed above is fixed (or committed) in the short term with respect to production volume. These costs are considered "wasted" when capacity utilization is low.

There are several approaches that one can take to determine which costs to consider as fixed. Following the notion of account analysis, we first evaluate each of the cost components individually and classify them as either 'fixed' or 'variable'. In particular, we classify the following components as fixed:

- 'All other salaries and wages'

- 'Total employer's cost of fringe benefits (supplemental labor costs)'

- 'Total depreciation charges for the year'

- 'Total rental payments'

Our rationale for this classification is that these cost categories are committed in the short run, either due to contractual obligations, or due to illiquidity in the factor markets (machines cannot be leased in and out at will).

We classify the following cost components as variable:

- 'Cost of materials, parts, components, containers, etc., used'

- 'Cost of products bought and sold as such'

- 'Cost of fuels'

- 'Cost of purchased electricity'

- 'Cost of contract work done for you by others'

- 'Production workers' wages' 
We also create two other classifications of fixed costs in order to provide some robustness for our analyses. We first create a lower bound of fixed costs, classifying only 'Total depreciation charges for the year', and 'Total rental payments' as fixed. That is, all labor and material cost components are considered variable. Our rationale here is that workers are probably more easily hired than fired than machinery, which probably cannot be leased in and out at will.

We then create an upper bound estimate of fixed costs where we classify 'All other salaries and wages', 'Total employer's cost of fringe benefits (supplemental labor costs)', 'Cost of fuels', 'Cost of purchased electricity', 'Total depreciation charges for the year', and 'Total rental payments' as fixed. In this permutation, only 'Production workers' wages', 'Cost of materials, parts, components, containers, etc., used', 'Cost of products bought and sold as such', and 'Cost of contract work done for you by others' are considered to be variable costs. Our rationale for these classifications is based on our considered judgment.

Graphs $5 \mathrm{a}$ and $5 \mathrm{~b}$ show the proportions of costs that are classified as fixed, including at the lower and upper bounds. Graph 5a shows the annual cross-sectional means for the entire sample. The proportion of costs classified as fixed varies between 17\% (in 1979) and 25\% (in 2002). Averaging across all years, fixed costs make up $20 \%$ of total costs, and $4 \%$ and $23 \%$ at the lower and upper bounds.

Graph $5 b$ shows the annual cross-sectional means of the fixed cost proportions, including the lower and upper bounds, for the 10 industries. Industry '20 - Food \& Kindred Products' has the lowest proportion of fixed costs at $12 \%(3 \%$ and $15 \%$ at the lower and upper bound, respectively). Industry '36 - Electronic \& Other Electric Equipment' has the highest proportion of fixed costs at $26 \%$. At the upper bound, '32 - Stone, Clay \& Glass Products' has the highest proportion at $31 \%$. 
An alternative approach for determining the proportion of fixed costs is a data-driven estimation. Specifically, we conduct the following analysis. We retain the 5,400 observations $(\sim 3.6 \%)$ in the sample where the establishment's level of available capacity (based on the variable 'market value of production at practical capacity utilization' in the PCU/ QPC survey) is the same for two consecutive years. We can then estimate a production cost curve, i.e., total cost as a function of total output, and use its intercept to estimate the proportion of fixed costs. Specifically, for each establishment-consecutive year pair, we have two (total cost, total output) data points. ${ }^{18}$ We fit a straight line between these two observations to estimate an intercept. We then estimate the proportion of fixed costs by taking the ratio of the estimated intercept to the average total cost. We acknowledge that this estimation procedure assumes a linear cost function.

Over all establishment-consecutive year pairs, we find that the median of the estimated fixed cost proportions is $26 \% .{ }^{19}$ This estimate is consistent with the results of the approach using account analysis discussed above and depicted in Graphs 5a and 5b. We therefore use the fixed cost estimates based on the account analysis for the rest of the study.

\subsection{Impact of Excluding the Cost of Unused Capacity on Product Costs and Profit Margins}

In order to investigate whether excluding the cost of unused capacity materially reduces product costs, we take the following ratio:

(2) (Total $\operatorname{cost}_{\mathrm{pt}}-$ Cost of unused capacity $\left.\mathrm{pt}\right) /$ Total $\operatorname{cost}_{\mathrm{pt}}(\mathrm{p}=$ plant, $\mathrm{t}=$ year $)$

\footnotetext{
18 Total cost is the sum of all the three cost categories: labor, material, and depreciation. Total output is the sum of 'total value of shipments', 'change in finished goods inventory', and 'change in work-in-process inventory'. All dollar-based data are adjusted for inflation. See Appendix B for details.

${ }^{19}$ The Census allowed the publication of this median figure, because it does not identify a particular establishment.
} 
Total cost is the sum of all the three cost categories: labor, material, and depreciation (see Appendix B), and the cost of unused capacity is defined in equation (1).

Graphs $6 \mathrm{a}$ and $6 \mathrm{~b}$ show the cross-sectional means of this ratio over time. Graph 6a shows the annual cross-sectional means for the entire sample. The average reduction in costs across all years is $6 \%$ and varies between $4 \%$ in 1979 and $10 \%$ in 2009. At the lower bound of the fixed costs the reduction across all years is $1 \%$; at the upper bound it is $7 \% .{ }^{20}$

Graph $6 \mathrm{~b}$ shows the annual cross-sectional means of the ratio in (2), including at the lower and upper bounds of fixed costs, for the 10 industries. At 3\%, the average cost impact across all years is lowest for ' 20 - Food \& Kindred Products'. The highest impact at 9\% is experienced by industry ' 35 - Machinery \& Equipment'. At the lower bound of fixed costs, the cost impact is approximately $1 \%$ for all of the 10 industries. At the upper bound of fixed costs, the cost impact is between $0 \%$ and 3\% higher. Across all industries and years, the average cost reduction is $6 \%$.

The cost reduction above appears to be material, given the sensitivity of stock prices to small changes in various measures of reported margins (Bradshaw and Sloan 2002). We therefore margins explicitly by comparing profit margins that include the cost of unused capacity to the profit margins that exclude the cost of unused capacity.

Computing the profit margin requires some care because sales and production may not be fully matched: This year's shipments may arise from last year's production, and this year's production may go into inventory. In order to match the current year's production costs, we follow the standard economics approach detailed in Foster et al. (2014) and compute current

\footnotetext{
${ }^{20}$ We do not display p-values because removing unused capacity costs (if any) weakly reduces reported costs with probability one. When we computed p-values, they were 0.000 .
} 
year's productive output by: 'Total Value of Shipments' + 'Value of Finished Goods Inventory at End of Year' - 'Value of Finished Goods Inventory at Beginning of Year' + 'Value of Workin-Process Inventory at End of Year' - 'Value of Work-in Process Inventory at Beginning of Year' (see Appendix B). We recognize that some of these items are recorded at cost and some at price, but this limitation is shared by all studies that use this data (Foster et al. 2014).

We compute the profit margins including and excluding the cost of unused capacity (see equation (1) for the definition of the cost of unused capacity) as follows:

(3a) Unadjusted profit $\operatorname{margin}_{\mathrm{pt}}=\left(\right.$ Productive output $_{\mathrm{pt}}-$ Total production costs $\mathrm{pt}_{\mathrm{t}} /$ Productive output $_{\mathrm{pt}}$

(3b) Adjusted profit $\operatorname{margin}_{\mathrm{pt}}=\left(\right.$ Productive output $_{\mathrm{pt}}-\left(\right.$ Total production $\operatorname{costs}_{\mathrm{pt}}-$ Cost of unused capacitypt $) /$ Productive output $\mathrm{pt} \quad(\mathrm{p}=$ plant, $\mathrm{t}=$ time $)$

Note that theses measures of profit margin do not include any costs incurred at the corporate level, such as financing costs or income taxes.

Graphs $7 \mathrm{a}$ and $7 \mathrm{~b}$ show the annual cross-sectional means of four profit margins over time: The unadjusted margin that includes the cost of unused capacity, and three adjusted margins where the cost of unused capacity is excluded, based on the three estimates of fixed costs discussed above. Graph 7a shows the annual cross-sectional means for the entire sample. ${ }^{21}$ Across all years, the unadjusted profit margin has a mean of 0.19 , and the adjusted profit margin has a mean of 0.24 ( 0.25 and 0.20 at the upper and lower bound, respectively). Differences in

\footnotetext{
${ }^{21}$ In order to reduce the influence of outliers, we winsorize the sample at the $1^{\text {st }}$ and $99^{\text {th }}$ percentile. Specifically, we sort the sample into 100 buckets each year based on the profit margins, and set the values of the observations in the $1^{\text {st }}$ and $100^{\text {th }}$ bucket to be the means of the $2^{\text {nd }}$ and the $99^{\text {th }}$ bucket, respectively. We take this approach because the Census does not permit imputation using the value of a specific plant.
} 
means tests indicate that the means of all three of the adjusted profit margin measures are significantly different from the mean of the unadjusted profit margin $(0.19)$ at the $p=0.0000$ level.

Graph 7a indicates that excluding the cost of unused capacity increases profit margins by, on average, $26 \%(0.24 / 0.19)$. This number is economically significant, considering how sensitive stock prices are to profit measures (Burghstahler and Dichev 1997), and considering the effort that firms put into defining profit figures (Bradshaw and Sloan 2002). In fact, in Graph 8, we plot (winsorized) Compustat ratios of (sales - COGS)/sales and net income/sales for the 2digit SIC codes in Table 2 in the years listed in Table 1. Graph 8a shows that Compustat operating profits are similar in range to Graph 7a, suggesting that the magnitudes of changes we observe in our data should also happen in the reported data to external investors. This in turn can potentially have significant stock price impact, and could explain why some firms, whose management has presumably come to same conclusion as us, are taking pains to explicitly disaggregate excess capacity data (see our Exhibit 1).

Graph $7 \mathrm{~b}$ shows the annual cross-sectional means of the four profit margins for the 10 industries. The largest change in the profit margin at $47 \%$ is experienced by industry ' 37 Transportation Equipment', which is the industry with the lowest capacity utilization (see Graph $2 \mathrm{~b}$ and discussion above). The smallest change at $11 \%$ is experienced by industry ' 20 - Food \& Kindred Products', which is characterized by high capacity utilization and by the lowest proportion of fixed costs (see Graphs $2 \mathrm{~b}, 5 \mathrm{~b}$ and discussion above).

A potential concern with any margin ratio analysis is that small denominators drive the results. This is unlikely to be the case in our setting for several reasons. First, we have winsorized the margins (see Appendix B). Second, we show in Graph 6 that costs, which are in 
the margin numerator, also change in the same manner as margins do in Graph 7; the variation in profit margins is thus unlikely to be entirely driven by the small denominator effect. Finally, Graphs $7 \mathrm{a}$ and $7 \mathrm{~b}$ show that the change in profit margins is pervasive across industries and across time.

\subsection{Impact of Excluding the Cost of Unused Capacity on the Time Series Variation of Unitized Product Costs and Profit Margins}

Having established that excluding the cost of unused capacity materially reduces product costs and materially increases profit margins, we now examine the time-series variation of the unitized product costs and profit margins (hypothesis H2).

Developing a measure of unitized product costs requires dividing the total production costs by a measure capturing the total production volume. Since the datasets do not include information on the number of units produced, we use the ratio (Total costs/ Productive output) (see Appendix B) as a proxy for unitized product costs. Recall that our measure of profit margin is:

[(Productive output - Total Costs)/ (Productive Output)], which is equivalent to:

$$
[1-(\text { Total costs/ Productive Output) }] \text {. }
$$

Thus, the standard deviations of our measures of unitized product costs and profit margin are the same. For expositional purposes, we present the standard deviations of the profit margins, whose annual cross-sectional means are depicted in Graphs 7a and 7b.

For each establishment, we calculate the standard deviations of the unadjusted and adjusted profit margins (i.e. profits margins with and without unused capacity), respectively over 
all available years. Since the resulting distributions of the two standard deviations follow a lognormal pattern, we apply a log-transformation before conducting differences in means tests. For the entire sample, the mean of the distribution of the standard deviations of the adjusted profit margins is significantly lower than the mean of the distribution of the standard deviations of the unadjusted profit margins $(\mathrm{p}=0.0000)$. This result is consistent with the visual inspection of Graph $7 a^{22}$

With respect to the individual industries, we find that the standard deviations of the adjusted profit margins are significantly lower than the standard deviations of the unadjusted profit margins at the $\mathrm{p}=0.0000$-level in all but two of the industries: there is no statistically significant difference in the standard deviations for industries '20 - Food \& Kindred Products' and '23 - Apparel \& Other Textile Products'. One reason could be that these two industries have relatively low costs of unused capacity - they are the industries with the lowest proportion of fixed costs and the higher capacity utilization, respectively.

In sum, the results indicate that for the entire sample and for the majority of the industries, excluding the cost of unused capacity does indeed reduce the time-series variation of unitized product costs and profit margins. This finding should be of great interest to management and investors, who wish for a profit margin that is not just high but also stable over time (e.g., Burgstahler and Dichev 1997).

Our finding is also consistent with the argument developed in HBS cases such as 'Anagene, Inc.' that incorporating unused capacity into product costs simply transmits the volatility of unused capacity to product margins. However, as discussed in section 2 , the above argument assumes that the only variation arises from variations in the number of units produced.

\footnotetext{
${ }^{22}$ Note that subtracting a positive number $\mathrm{c}$ from the profit margin $\mathrm{p}$ surely reduces the mean, but not necessarily the variance. $\operatorname{Var}(p-c)=\operatorname{Var}(p)+\operatorname{Var}(c)-2 \operatorname{Covar}(p, c)$. Whether the variance increases of decreases depends on how $c$ is correlated with $\mathrm{p}$.
} 
If other factors such as production costs also vary production volume, then there is no reason to believe that removing unused capacity should reduce the time-series variation in profit margins, e.g., the insignificant results for industries '20 - Food \& Kindred Products' and '23 - Apparel \& Other Textile Products' could arise not just from low levels of unused capacity but also from these other offsetting factors. We therefore explore whether labor and material unit costs are increasing in the level of capacity utilization for reasons such as congestion and overtime pay.

The standard way to estimate if the productivity of labor and material inputs is affected by capacity is to run an input-output regression with the relevant interactive effects. We follow the economics literature and run standard total factor productivity (TFP) regressions that include the level of capacity utilization and its interaction with labor and material inputs.

The measurement of production efficiency is a rich economics literature, whose methodology is summarized in detail in Foster et al. (2014). This literature regresses annual establishment output on labor, material, energy, and capital usage, all in logs. ${ }^{23}$ Given the lag between production and sales, this literature measures output using both inventory changes and shipments. Furthermore, capital is an asset, and the literature makes several assumptions to estimate periodic capital usage. In fact, the Census has created special datasets ASMTFP and CMTFP, where all the input and output variables have been pre-calculated for ASM/ CM establishments.

As described in detail in Table 3, we use the ASMTFP and CMTFP datasets. Our only modification is to interact the labor, capital, material, and energy inputs with the capacity utilization measure. In addition, we also include establishment-SIC interaction fixed effects to control of establishment fixed effects and production technology change events where

\footnotetext{
${ }^{23}$ The log transformation linearizes the standard Cobb-Douglas production function and makes it amenable to a linear regression.
} 
establishments switch industries. Note that the ASMTFP and CMTFP datasets have fewer observations than the ASM dataset. Table 3 therefore has approximately 62,400 establishmentSIC interaction observations as opposed to our original 151,900 observations (recall Census requires us to round the number of observations).

Table 3 presents the results. Model 1 simply includes all the input factors, all of which have a significantly positive correlation with output, as expected. Model II includes capacity utilization as an additional regressor, which is significantly positive. This is economically consistent with the idea that when the same workers work more efficiently with the same material and produce more, the effect can be seen in the machines running longer, i.e., higher capacity utilization.

Model III presents the interactive effects. The interactive effects of material and labor with capacity utilization are significantly negative, consistent with the diminishing marginal return economics of a typical manufacturing process. When machines are running at high capacity, adding more workers or material increase increases congestion and reduces the marginal productivity of these factors. Or conversely, workers and material are highly efficient at high levels of excess capacity. In this sense, excess capacity is not a fully wasted cost; it has the shadow benefit of making other factors more productive, which must be accounted for in the measurement of true product costs.

The coefficients of Table 3, Model III help us estimate the shadow effects of excess capacity. For labor and material, the interaction effects are an order of magnitude lower than the main effects. Switching from zero to full capacity utilization is not going change the marginal product of these factors significantly. Therefore, the accounting effects of including or excluding excess capacity in these factors will dominate any shadow economic effects. In other words, the 
results suggest the case in Section 2 where $\mathrm{V}$ is constant or has a low covariance with $\mathrm{N}$, in which case excluding unused capacity not only increases the profit margin but also reduces its time-series variation.

One way to reduce congestion is to increase machine capacity. The significantly positive interactive effects of capital with capacity utilization in Table 3, Model III suggests exactly that. The marginal benefits of more capital are highest when the plant is running at capacity.

In contrast to labor and material, the magnitude of the equipment capital interaction factor in Table 3, Model III is half the magnitude of its main effect. So, switching from zero to full capacity utilization can change the marginal product of this factor. However, as Graphs 4a and 5a show, depreciation is the smallest cost category. In fact, Graph 7a shows that much of the change to reported product profit occurs when part of labor considered as a fixed cost and incorporated into the excess capacity calculation. In sum, therefore, we conclude that diminishing marginal returns and shadow cost economics while present, are dominated by pure accounting considerations (i.e., the case in Section 2 where $\mathrm{V}$ is constant or has a low covariance with $\mathrm{N}$ ), and removing unused capacity not only increases the mean margin but also stabilizes its time-series variation.

\section{CONCLUSION}

Standard management accounting texts and cases argue that including the cost of unused capacity in product costs can significantly distort these costs and mislead users (see footnote 1). These texts and cases advocate the cost of unused capacity be separated. Likewise, some firms also view unused capacity as a significant economic factor that is distinct from product costs and discuss it prominently in their annual reports and investor presentations (see our Exhibit 1). 
Whether such rationales are justified in the cross-section of US firms is fundamentally an empirical question that requires detailed plant-level data. Such data are typically not public at the large-sample level, and must be obtained from government agencies such as the Census. This is an intensely time-consuming and bureaucratic process, subject to arbitrary delays and confidentiality checks and other idiosyncrasies of the US Federal Government.

This study is an attempt to overcome these data obstacles and provide a detailed and comprehensive description of the impact of excluding the cost of unused capacity on product costs and profit margins. Our confidential Census sample comprises of 151,900 U.S. manufacturing plants from 1974-2011. In this sample, we find that separating the cost of unused capacity decreases product costs on average by $6 \%$ and increases profit margins by $26 \%$. These numbers are economically significant given how sensitive stock prices are to reported margins. We additionally find that excluding unused capacity also smooths the time-series variation in reported margins, an issue of considerable interest to both managers and investors (e.g., Burgstahler and Dichev 1997).

Exhibit 1 of our study points to a potential path for future research. We have shown that accounting for unused capacity impacts both the mean and the time-series variation of reported profit margins. Given the ongoing debate on whether reported margins and other accounting data are priced risk factors (e.g., Core et al. 2008), our findings on first-moment and second-moment properties suggest that incorporating unused capacity into this literature could be a promising research endeavor. 


\section{REFERENCES}

Anderson, S. 1995. Measuring the impact of product mix heterogeneity on manufacturing overhead cost. The Accounting Review 70(3): 363-387.

Banker, R., D. Byzalov, and L. Chen. 2013. Employment protection legislation, adjustment costs and cross-country differences in cost behavior. Journal of Accounting and Economics 55: 111-127.

Banker, R., S. Datar, and S. Kekre. 1988. Relevant costs, congestion and stochasticity in production environments. Journal of Accounting and Economics 10: 171-197.

Banker, R., G. Potter, and R. Schroeder. 1995. An empirical analysis of manufacturing overhead cost drivers. Journal of Accounting and Economics 19: 115-137.

Bens, D., P. Berger, and S. Monahan. 2011. Discretionary disclosure in financial reporting: An examination comparing internal firm data to externally reported segment data. The Accounting Review 86(2): 417-449.

Berleman, M., and J. Wesselhoft. 2014. Estimating aggregate capital stocks using the perpetual inventory method. Review of Economics 65: 1-34.

Bettinghaus, B., M., Debruine, and P. Sopariwala. 2012. Idle Capacity Costs: It Isn't Just the Expense. Management Accounting Quarterly 13: 1-7.

Bradshaw, M., R. Sloan. 2002. GAAP versus the Street: An Empirical Assessment of Two Alternative Definitions of Earnings. Journal of Accounting Research 40: 41-66.

Bruggen, A., R. Krishnan, and K. Sedatole. 2011. Drivers and consequences of short-term production decisions: Evidence from the auto industry. Contemporary Accounting Research 28(1): 83-123.

Burgstahler, D., I. Dichev. 1997. Earnings management to avoid earnings decreases and losses. Journal of Accounting and Economics 24: 99-126.

Cooper, R. and R. Kaplan. 1988. Measure costs right: Make the right decisions.

Harvard Business Review September-October: 96-103.

Cooper, R. and R. Kaplan. 1991. The Design of Cost Management Systems. PrenticeHall, Englewood Cliffs, NJ.

Cooper, R. and R. Kaplan. 1992. Activity-based systems: Measuring the costs of resource usage. Accounting Horizons September: 1-13.

Core, J., W. Guay, and R. Verdi. 2008. Is accruals quality a priced risk factor? Journal of 
Accounting and Economics 46: 2-22.

Davis, S., J. Haltiwanger, and S. Schuh. 1996. Job Creation and Destruction, Cambridge: MIT Press.

Dierynck, B., W. Landsman, and A. Renders. 2012. Do managerial incentives drive cost behavior? Evidence about the role of the zero earnings benchmark for labor cost behavior in private Belgian firms. The Accounting Review 87(4): 1219-1246.

Foster, G., and M. Gupta. 1990. Manufacturing overhead cost driver analysis. Journal of Accounting and Economics 12: 309-337.

Foster, L., C. Grim, and J. Haltwinger. 2014. Reallocation in the great recessions: Cleansing or not? NBER working paper W20427.

Foster, L., J. Haltiwanger, and N. Kim. 2006. Gross job flows for the U.S. manufacturing sector: Measurement from the Longitudinal Research Database.

Working Paper.

Foster, L., J. Haltiwanger, and N. Kim. 2016. Reallocation in the Great Recession:

Cleansing or not? Journal of Labor Economics 34(1): S293-S331.

Horngren, C., S. Datar, and M. Rajan. 2015. Cost Accounting: A Managerial Emphasis. Upper Saddle River, NJ: Pearson Prentice Hall.

Kaplan, R. 1994. Flexible budgeting in an activity-based costing framework. Accounting Horizons June: 104-109.

Kaplan, R. and A. Atkinson. 1998. Advanced Management Accounting. Prentice-Hall, Engle- wood Cliffs, NJ.

Kreps, D. 1990. A Course in Microeconomic Theory. Princeton University Press.

McGuckin, R. and G. Pascoe. 1988. The longitudinal research database: Status and research possibilities. Survey of Current Business 68(11): 30-37.

Puri, M. and R. Zarutskie. 2012. On the life cycle dynamics of venture-capital and nonventure-capital-financed firms. The Journal of Finance (December): 2247-2293.

Young, C., C. Peng, C. Chien, and L. Tsai. 2014. Does SFAS No. 151 Trigger More Overproduction? Journal of Management Accounting Research 26: 121-143. 


\section{Exhibit 1 Disclosures of Excess Capacity \\ Amyris Q3 2016 Conference Call ${ }^{24}$ \\ Adjusted gross profit}

Adjusted cost of sales and gross profit

\begin{tabular}{lrrr}
\hline \$ millions & Q3 2015 & Q3 2016 & \% change \\
\hline Total revenues & 8.6 & 26.5 & $208 \%$ \\
& & & \\
Cost of product sales (GAAP) & 8.5 & 14.9 & $76 \%$ \\
Less: Inventory provisions/other cost & $(1.8)$ & 3.2 & $-278 \%$ \\
Less: Excess capacity & 1.9 & 0.3 & $-84 \%$ \\
Less: Depreciation & 1.0 & 1.0 & $0 \%$ \\
\hline Adjusted cost of sales & 7.4 & 10.4 & $41 \%$ \\
& & & \\
Adjusted gross profit & 1.2 & 16.1 & $1195 \%$ \\
Adjusted gross margin & $14.5 \%$ & $60.8 \%$ &
\end{tabular}

- $61 \%$ Adjusted gross margin led by higher mix of collaboration revenues and favorable product mix with no fuel sales

- Increase in inventory provision/cost mainly driven by reversal of inventory provision in Q3 2015

Copyright $\odot 2016$ Amyris, Inc. All rights reserved.

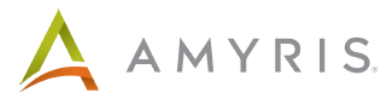

Ford 2015 Annual Report Disclosure of Excess Capacity Risk Factor (Item 1A)

Continued or increased price competition resulting from industry excess capacity, currency fluctuations, or other factors. The global automotive industry is intensely competitive, with manufacturing capacity far exceeding current demand. According to the December 2015 report issued by IHS Automotive, the global automotive industry is estimated to have had excess capacity of about 31 million units in 2015. Industry overcapacity has resulted in many manufacturers offering marketing incentives on vehicles in an attempt to maintain and grow market share [ .... ] Continuation of or increased excess capacity could have a substantial adverse effect on our financial condition and results of operations.

\footnotetext{
${ }^{24}$ Source: http://files.shareholder.com/downloads/ABEA-4QL2IU/3384402191x0x915263/A1800A3E-32F8-4D818E94-D49826221574/Q3 Earnings call_presentation-FINALpptx.pdf
} 
Table 1: Distribution of establishment (i.e., plant-level) sample across years ${ }^{\mathrm{a}}$

\begin{tabular}{cc} 
Year & $\mathbf{N}$ \\
\hline 1974 & 8,000 \\
1975 & 7,600 \\
1976 & 7,100 \\
1977 & 6,700 \\
1978 & 7,100 \\
1979 & 8,400 \\
1980 & 7,900 \\
1981 & 7,600 \\
1982 & 6,900 \\
1983 & 6,400 \\
1984 & 6,400 \\
1985 & 6,700 \\
1987 & 7,300 \\
1992 & 9,100 \\
1997 & 16,000 \\
2002 & 15,100 \\
2007 & 4,100 \\
2008 & 3,400 \\
2009 & 3,200 \\
2010 & 3,500 \\
2011 & 3,700 \\
\hline
\end{tabular}

\section{Total 151,900}

${ }^{\mathrm{a}} \mathrm{All}$ numbers are rounded to the nearest hundred. 
Table 2: Distribution of the establishment (i.e., plant-level) sample across industries within the manufacturing sector ${ }^{a, b}$

\begin{tabular}{llr} 
2-digit SIC Code & \multicolumn{1}{c}{ Description } & N \\
\hline 35 & Industrial Machinery \& Equipment & 18,100 \\
20 & Food \& Kindred Products & 16,800 \\
34 & Fabricated Metal Products & 15,000 \\
36 & Electronic \& Other Electric Equipment & 11,700 \\
28 & Chemicals \& Allied Products \\
33 & Primary Metal Industries & 10,900 \\
37 & Transportation Equipment & 8,900 \\
23 & Apparel \& Other Textile Products & 8,300 \\
32 & Stone, Clay, \& Glass Products & 7,100 \\
24 & Lumber \& Wood Products & 7,100 \\
& & 6,600 \\
Total & & $\mathbf{1 1 0 , 5 0 0}$
\end{tabular}

${ }^{\mathrm{a}} \mathrm{All}$ numbers are rounded to the nearest hundred.

${ }^{\mathrm{b}}$ These ten 2-digit SIC codes have the largest number of observations. 


\section{Graph 1: Size of establishments (i.e., plants) in the full sample}

\section{Graph 1a: Distribution of the log of producer inflated-adjusted total value of shipments*}

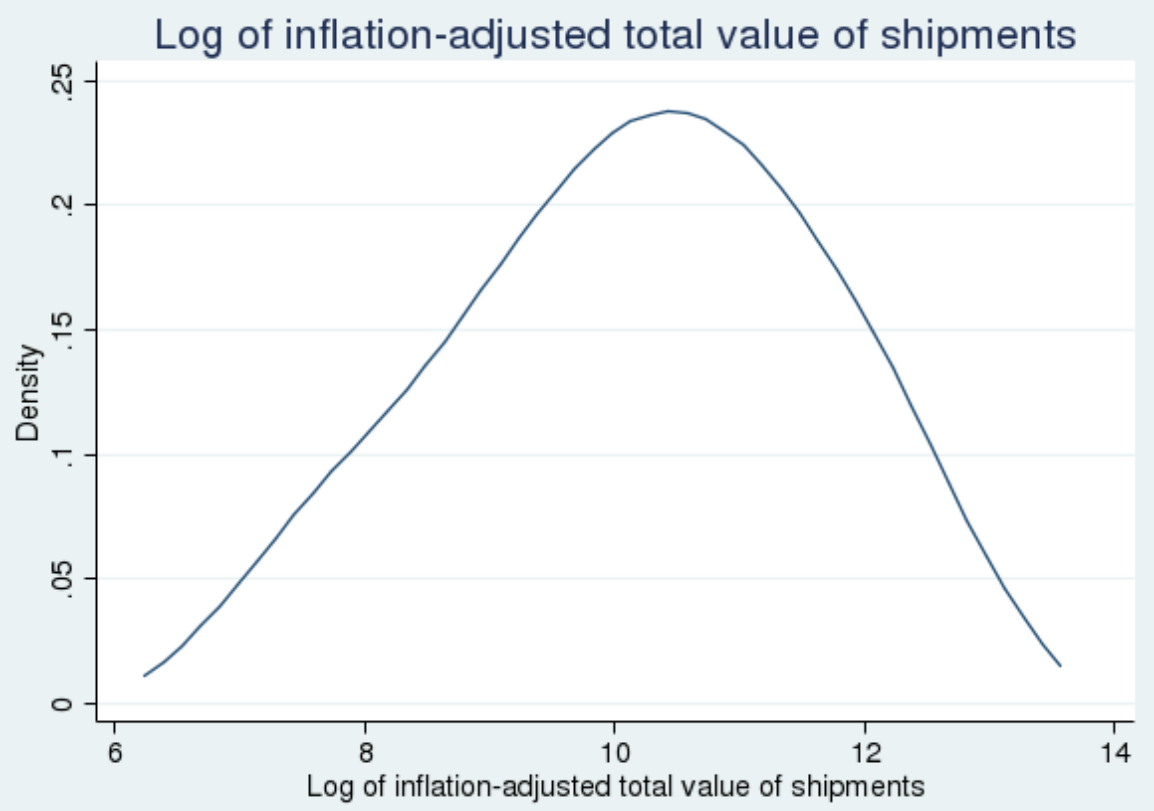

"Kernel density plot. Top and bottom 5\% are suppressed; $N=136,700$ (rounded). See Appendix B for variable definitions.

\section{Graph 1b: Mean producer inflation-adjusted total value of shipments by year*}

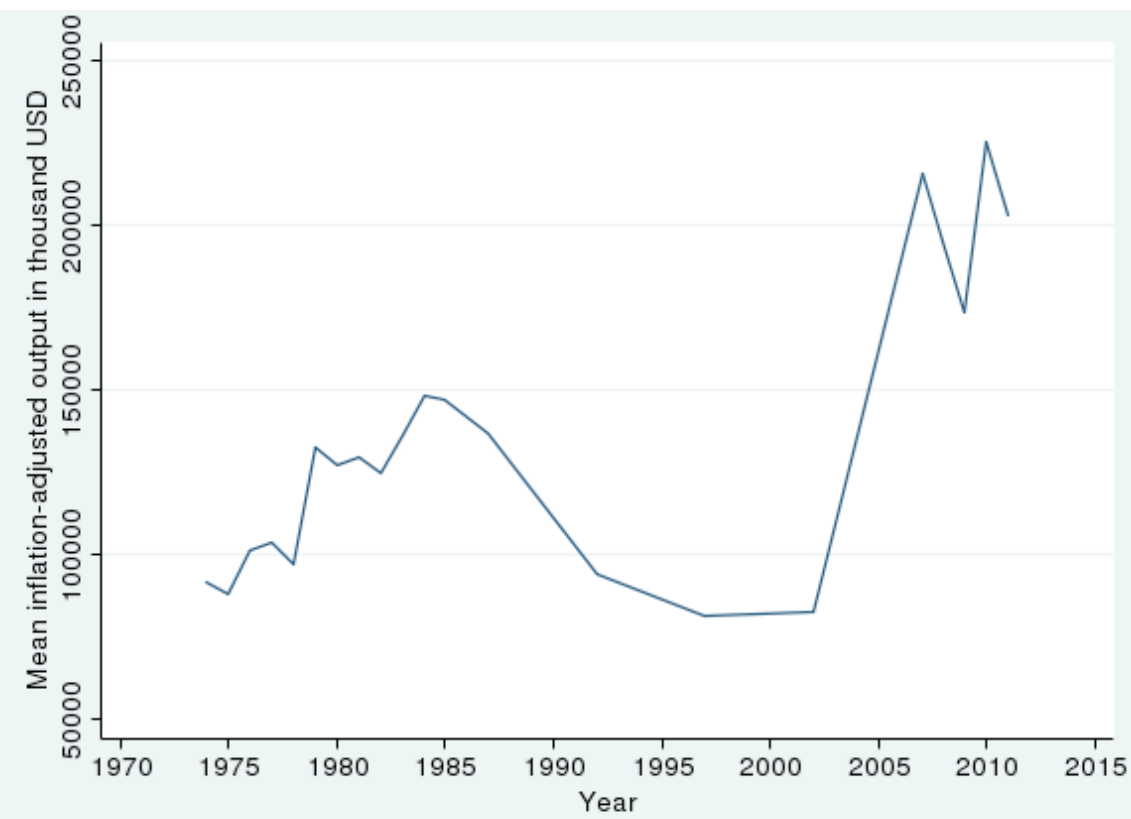

*Annual cross-sectional means of inflation-adjusted total value of shipments; $\mathrm{N}=151,900$ (rounded). See Appendix B for variable definitions. 


\section{Graph 2: Histogram of establishment (i.e., plant) capacity utilization for all years Graph 2a: Full sample*}

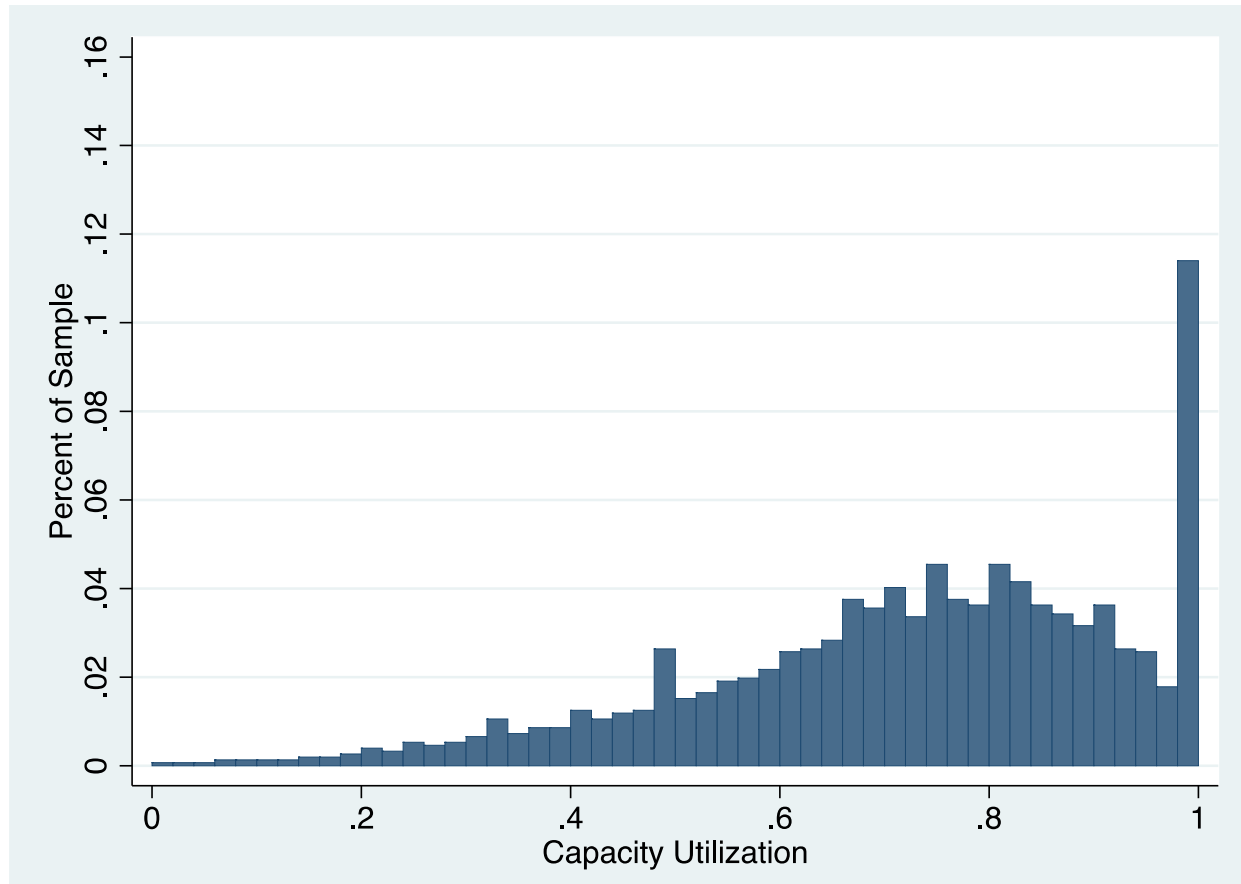

*Following the disclosure rules of the U.S. Census Bureau, we report the number of observations (rounded to the nearest hundred) in each bin; $N=151,900$ (rounded). See Appendix B for variable definitions. 
Graph 2b: Histogram of capacity utilization over all years in 2-digit industries*
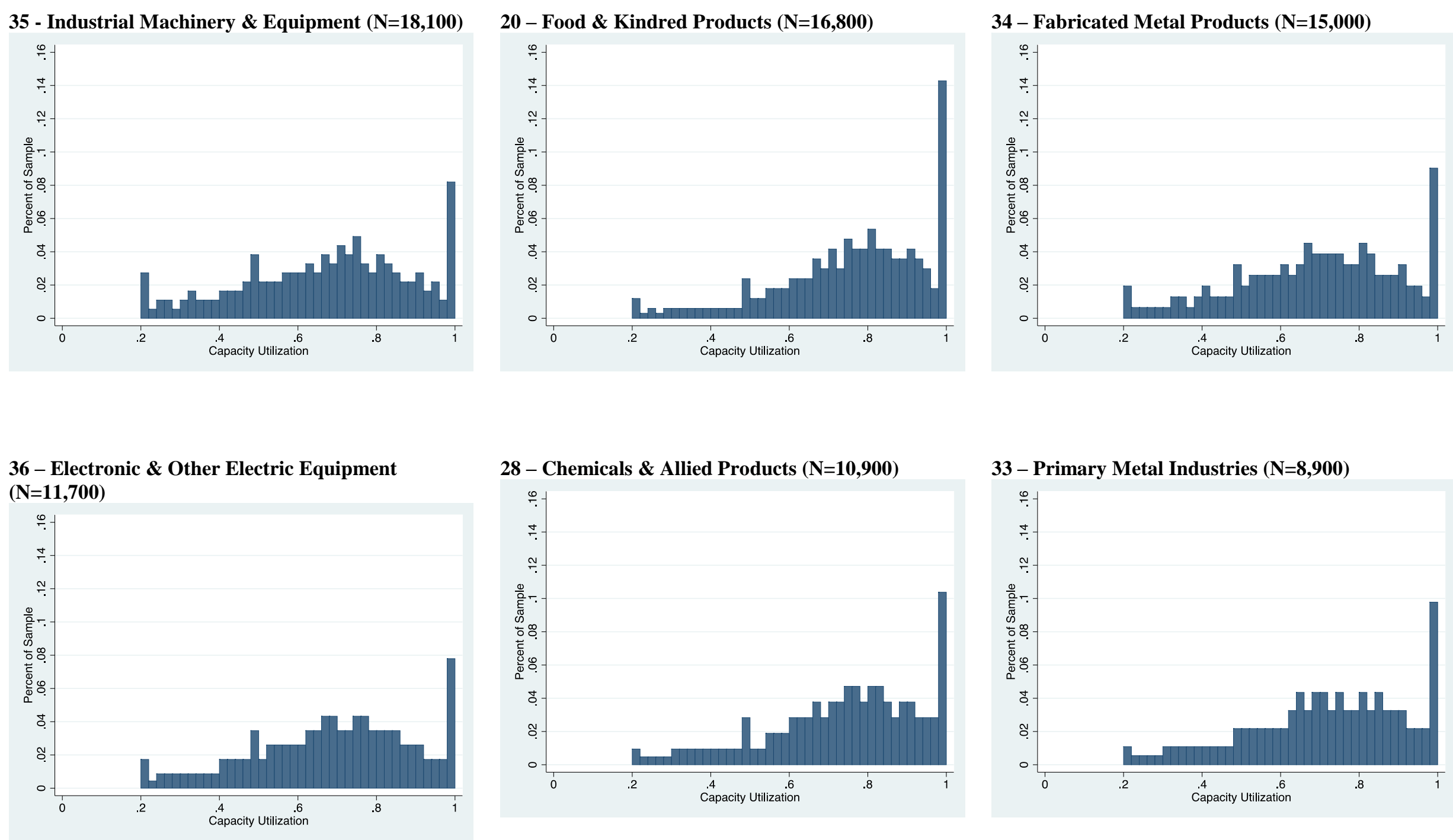
Graph 2b: (cont'd)
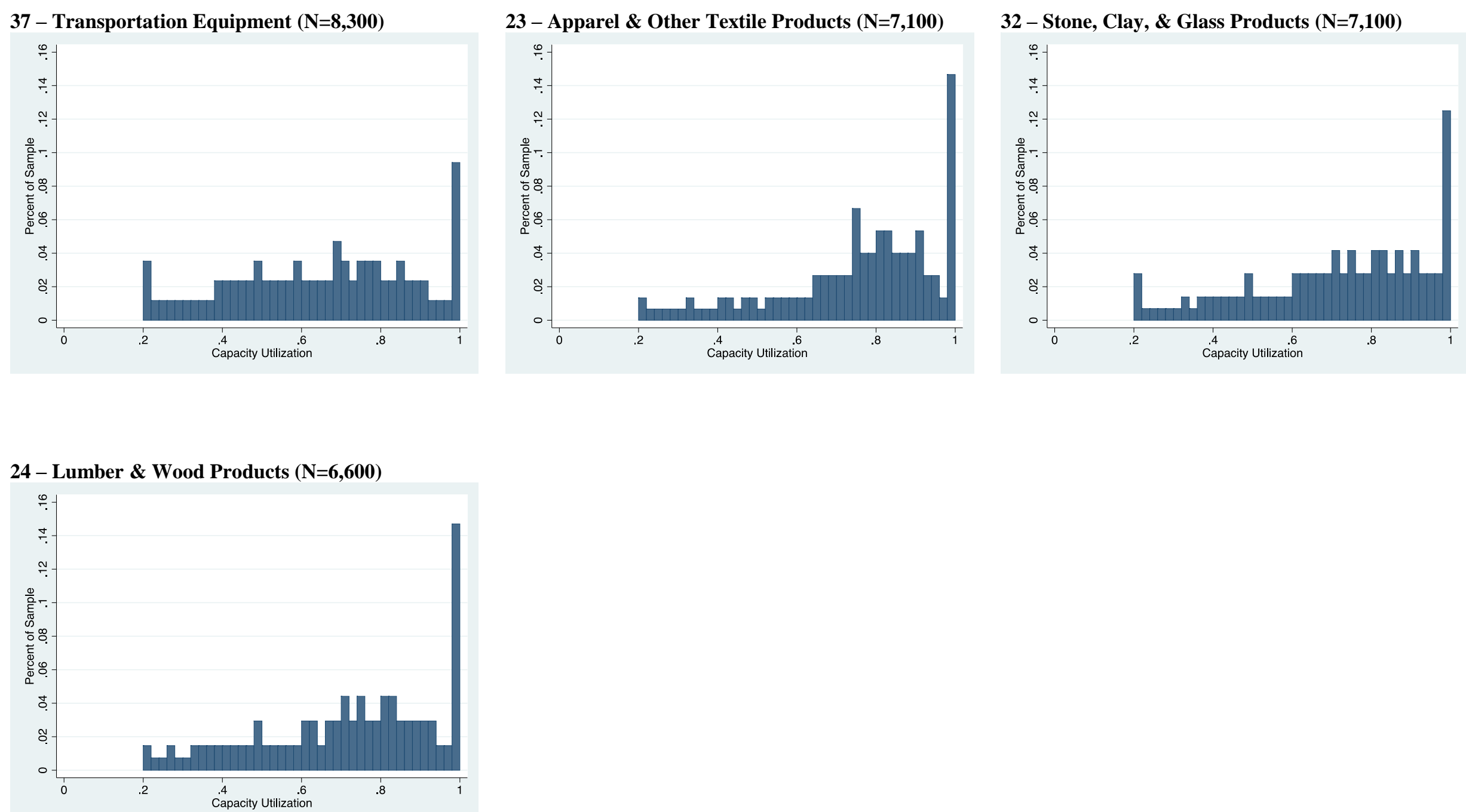

*Following the disclosure rules of the U.S. Census Bureau, we report the number of observations (rounded to the nearest hundred) in each bin. Observations with capacity utilization below 0.2 are included in the 0.2 bin since some of the lower bins do not meet the disclosure threshold; $\mathrm{N}=110,500$ (rounded). See Appendix B for variable definitions. 
Graph 3: Establishment (i.e., plant) capacity utilization over time Graph 3a: Full sample*

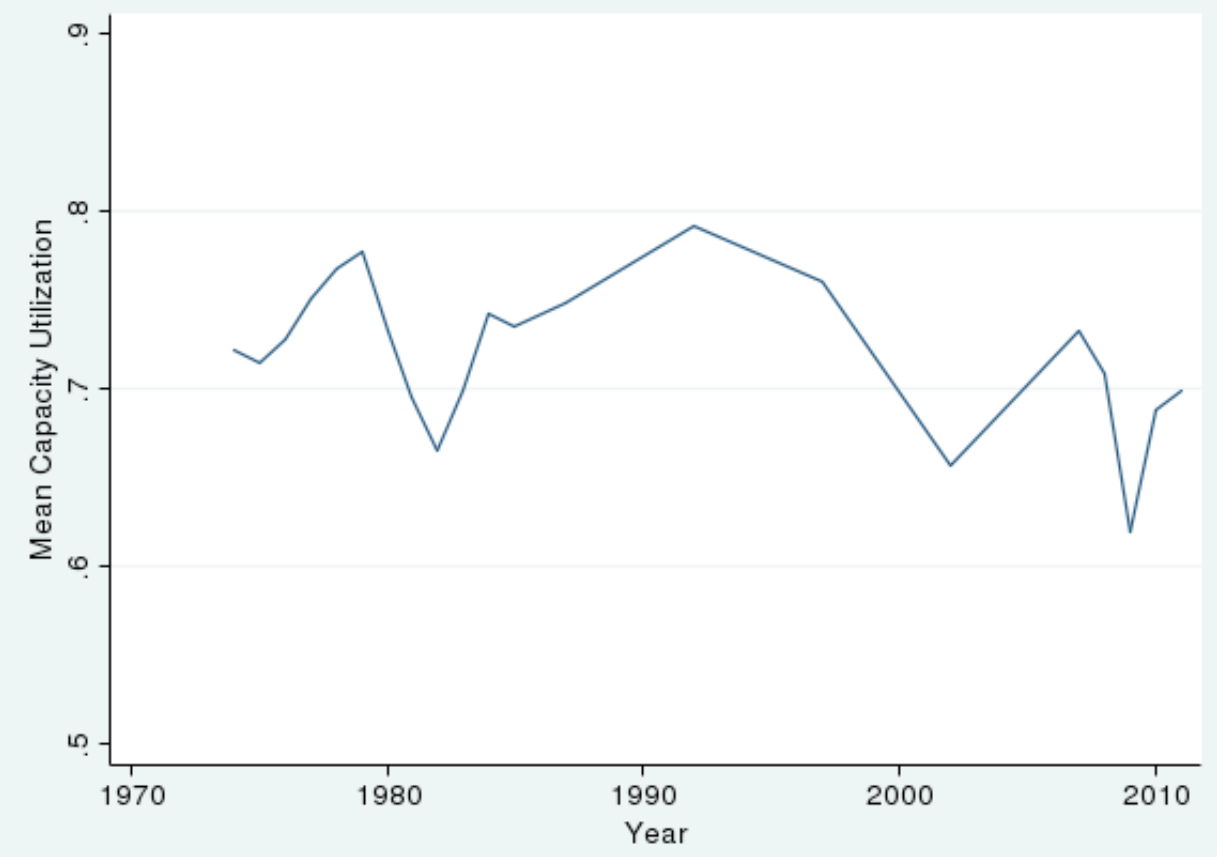

*Annual cross-sectional means of capacity utilization; $\mathrm{N}=151,900$ (rounded). See Appendix B for variable definitions. 


\section{Graph 3b: Capacity utilization over time in 2-digit industries*}

35 - Industrial Machinery \& Equipment (N=18,100)

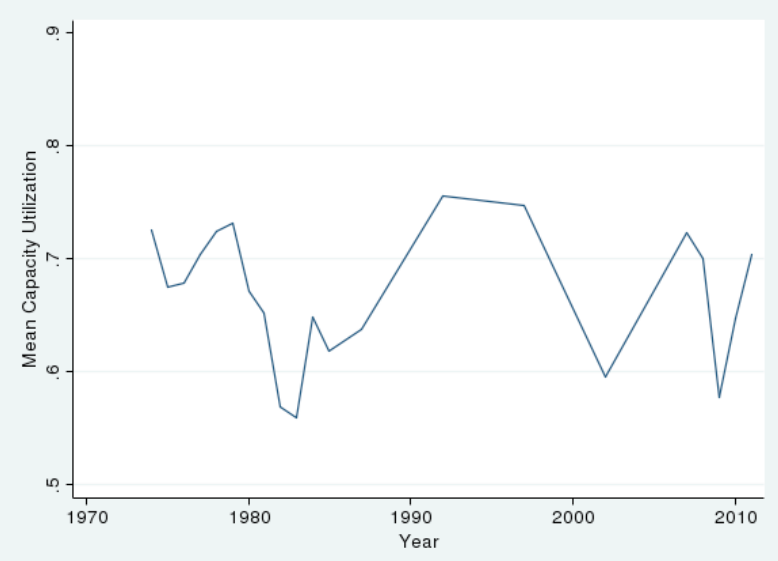

36 - Electronic \& Other Electric Equipment $(\mathrm{N}=\mathbf{1 1 , 7 0 0})$

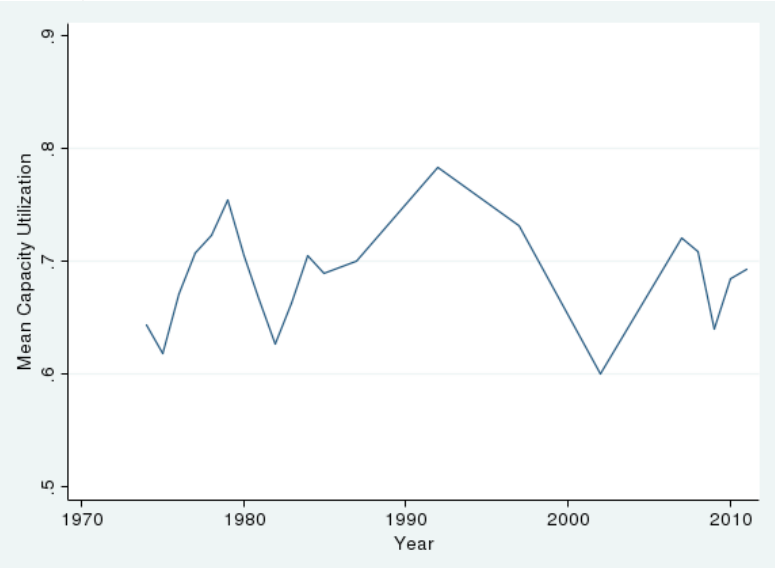

20 - Food \& Kindred Products $(\mathbf{N}=16,800)$

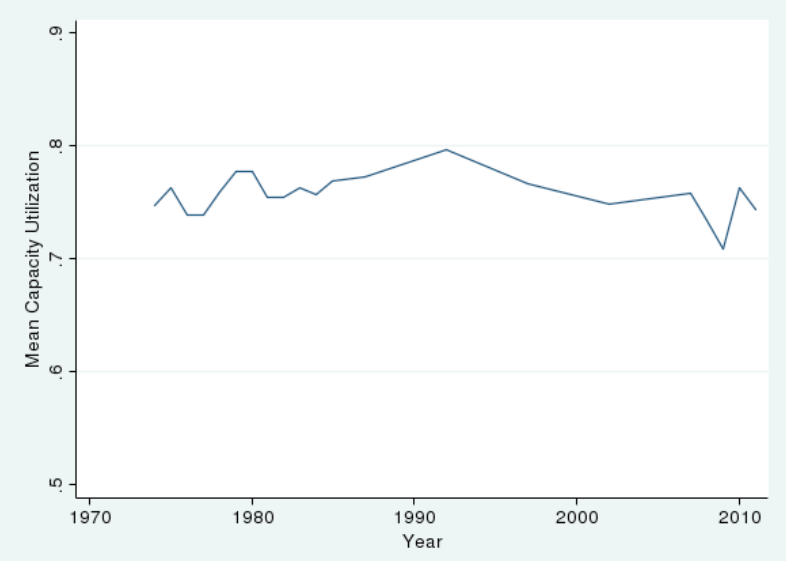

28 - Chemicals \& Allied Products $(\mathrm{N}=\mathbf{1 0 , 9 0 0})$

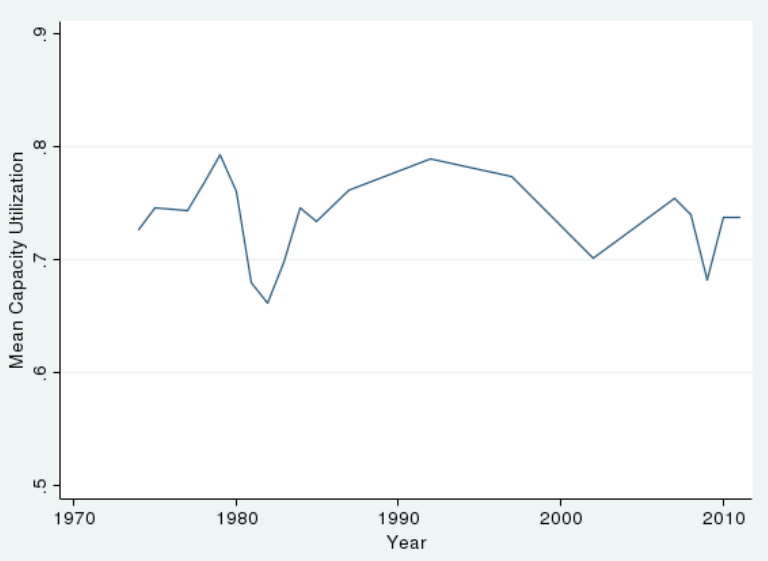

34 - Fabricated Metal Products $(\mathrm{N}=15,000)$

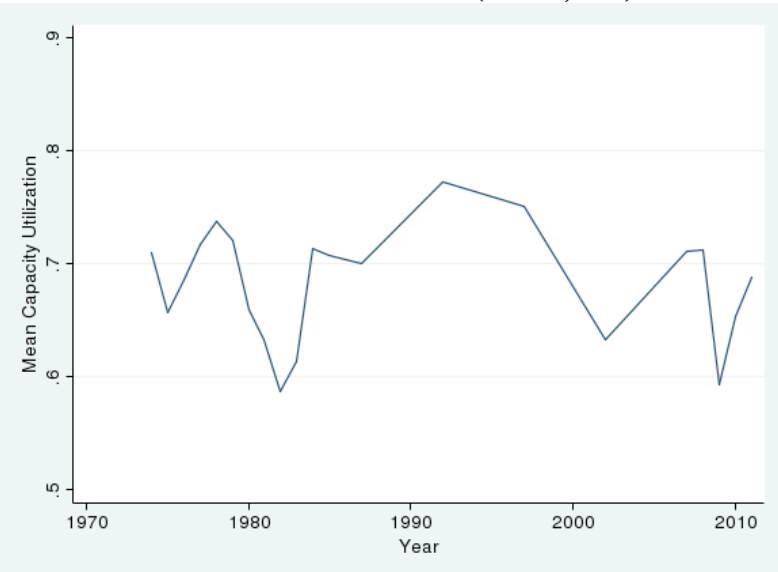

33 - Primary Metal Industries $(\mathbf{N}=\mathbf{8 , 9 0 0})$

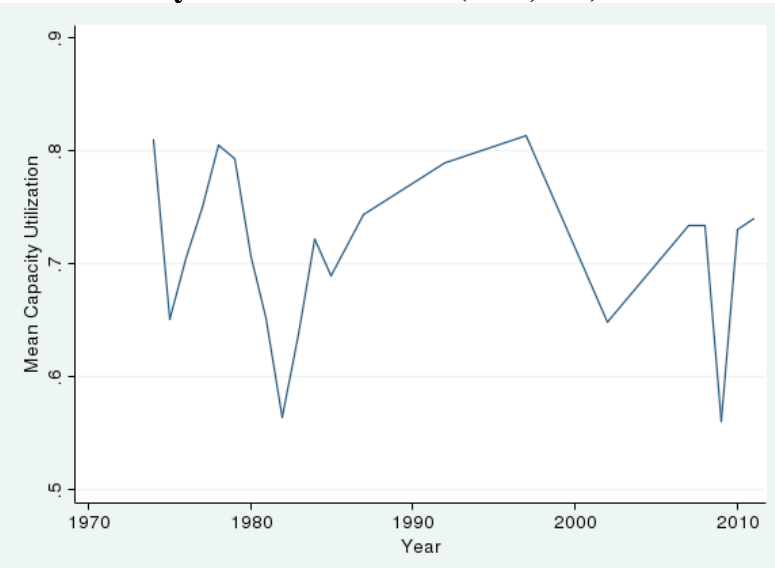


Graph 3b: (cont'd)

37 - Transportation Equipment $(\mathbf{N}=\mathbf{8 , 3 0 0})$

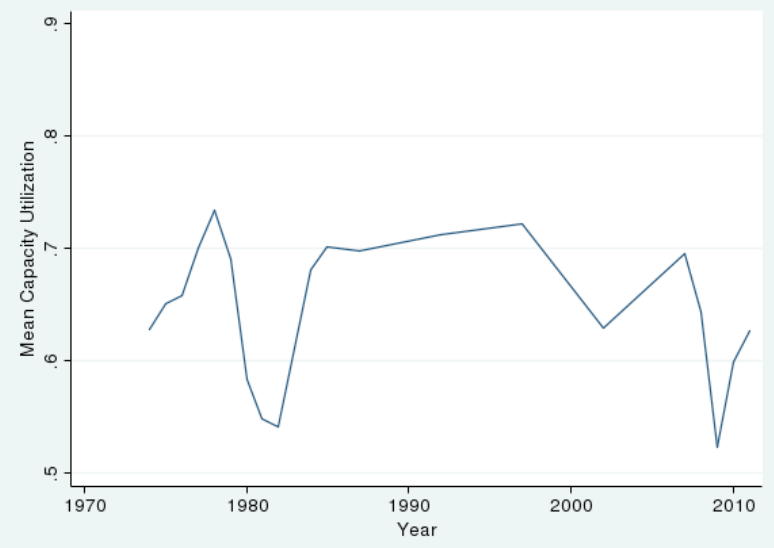

23 - Apparel \& Other Textile Products $(\mathrm{N}=7,100)$

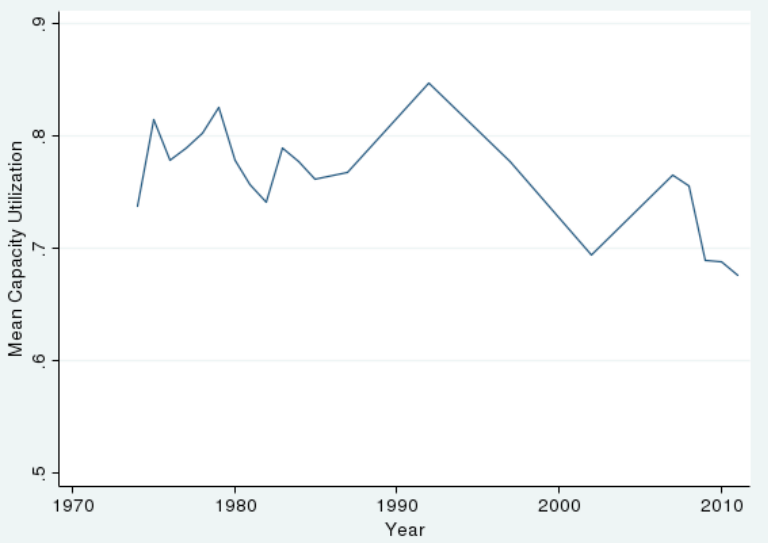

32 - Stone, Clay, \& Glass Products $(\mathrm{N}=7,100)$

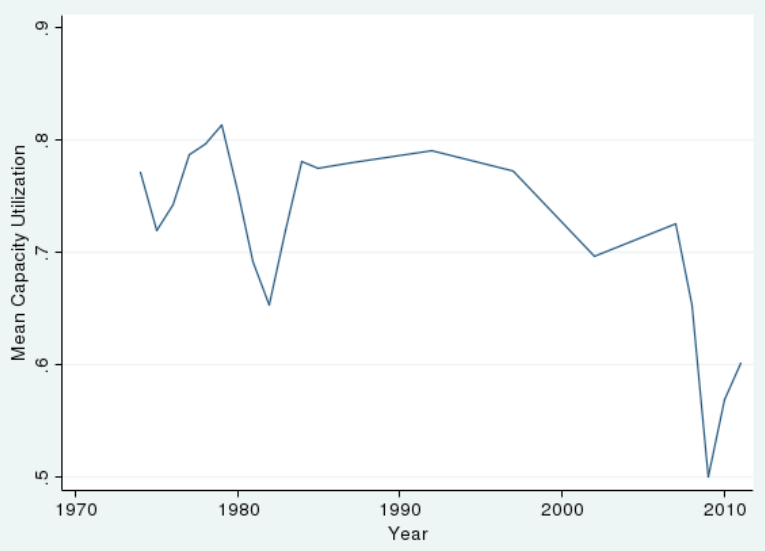

24 - Lumber \& Wood Products $(\mathrm{N}=6,600)$

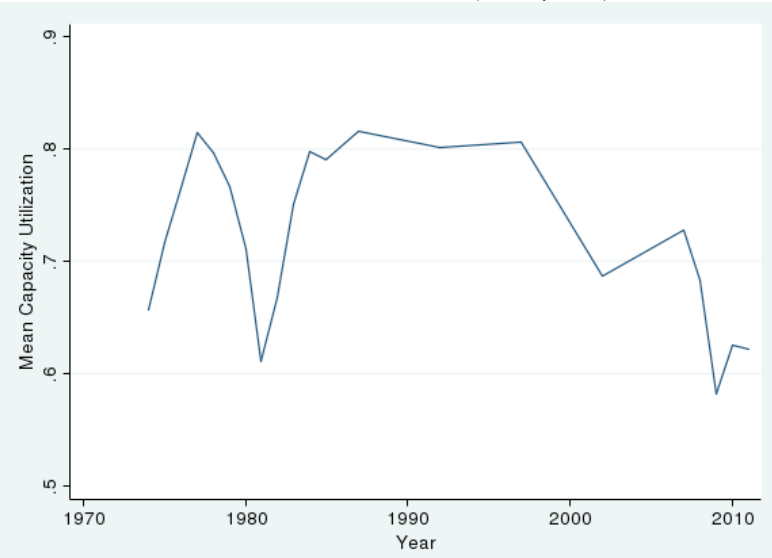

*Annual cross-sectional means of capacity utilization; $N=110,500$ (rounded). See Appendix B for variable definitions. 
Graph 4: Decomposition of total annual product cost into depreciation, labor, and material components for establishments (i.e., plants) over time

\section{Graph 4a: Full sample*}

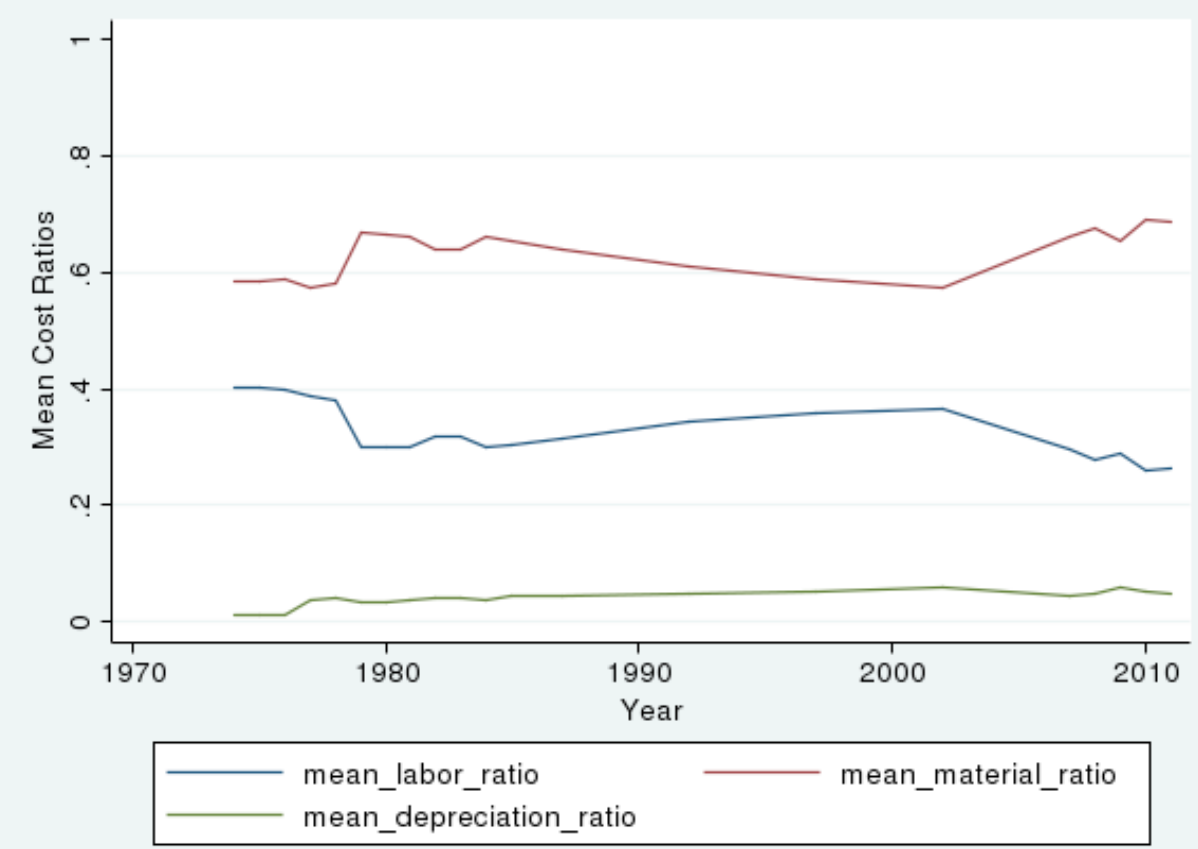

*Annual cross-sectional means of the proportions of the three cost components; $N=151,900$ (rounded). See Appendix B for variable definitions. 
Graph 4b: Mean cost ratios of material (top), labor (middle), and depreciation (bottom) costs to total annual product costs across 10 size buckets of inflation-adjusted total value of shipments for 151,900 establishments over all sample years [XXX I've replaced by the color-version $]^{*}$

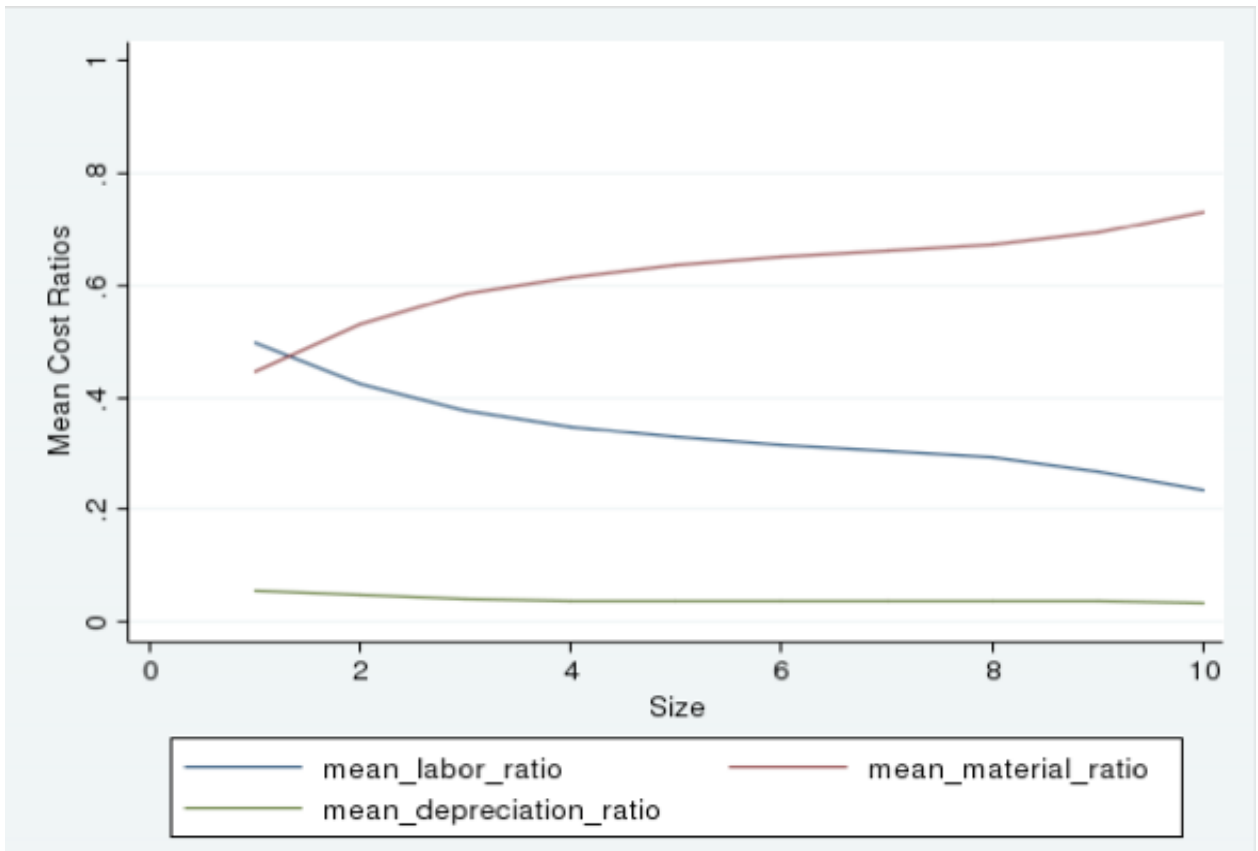

${ }^{*}$ See Appendix B for variable definitions. 
Graph 4c: Decomposition of total product cost into depreciation, labor, and material components over time in 2-digit industries*

35 - Industrial Machinery \& Equipment

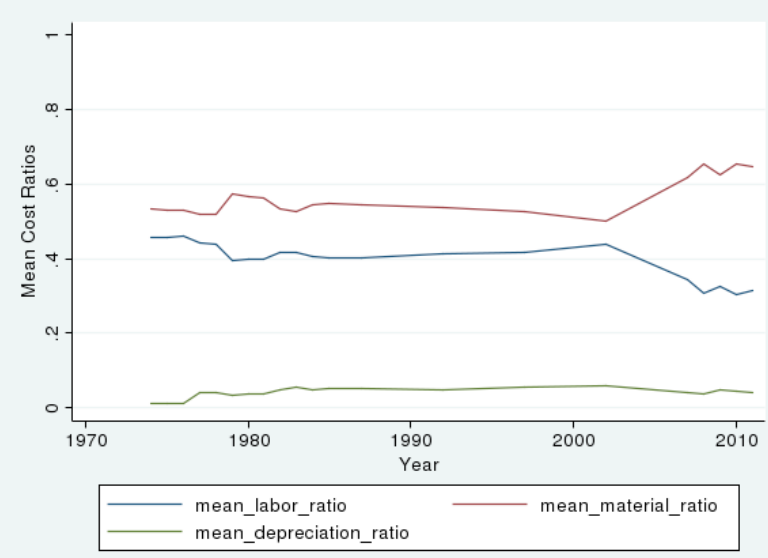

36 - Electronic \& Other Electric Equipment

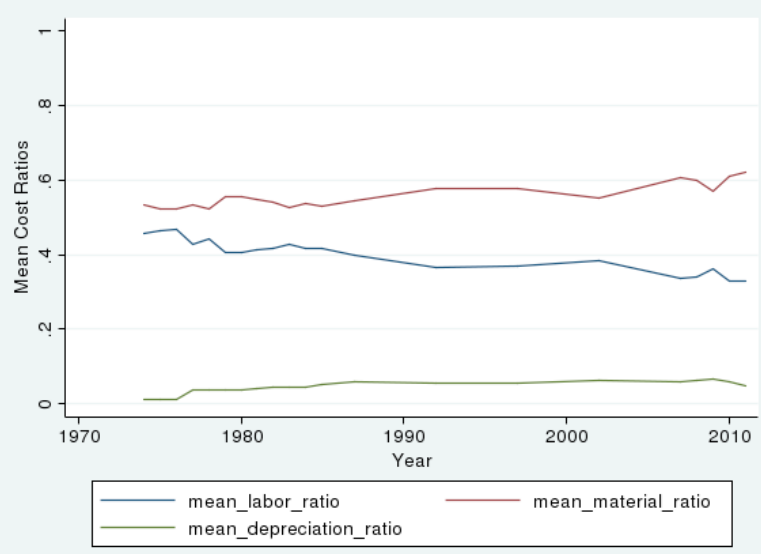

20 - Food \& Kindred Products

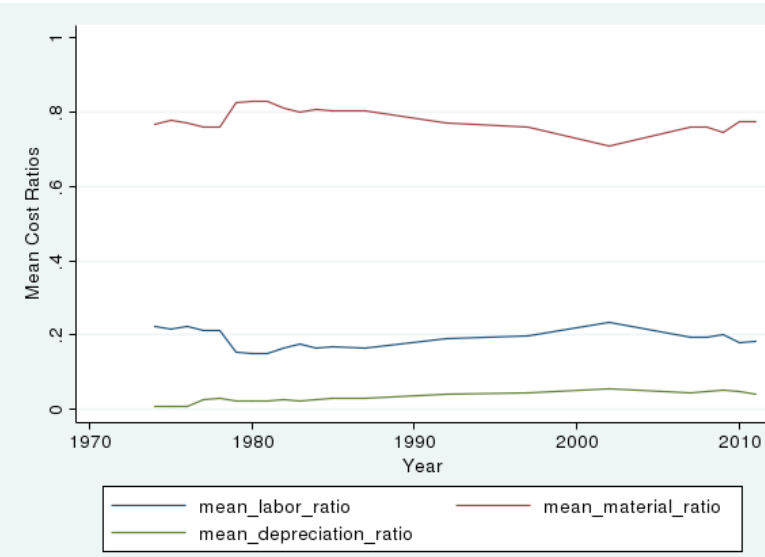

28 - Chemicals \& Allied Products

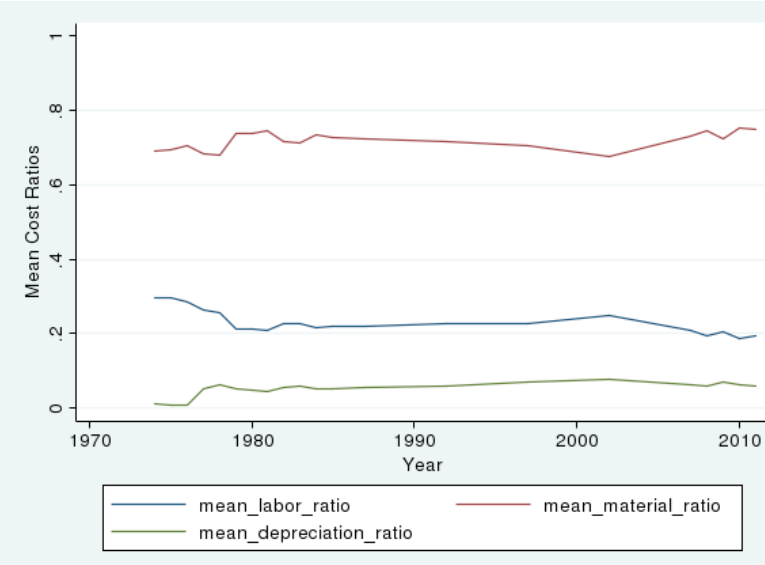

34 - Fabricated Metal Products

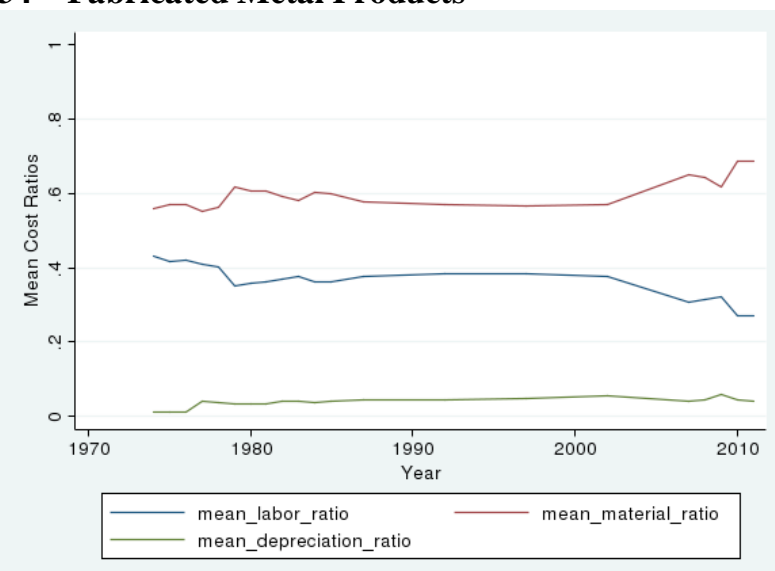

33 - Primary Metal Industries

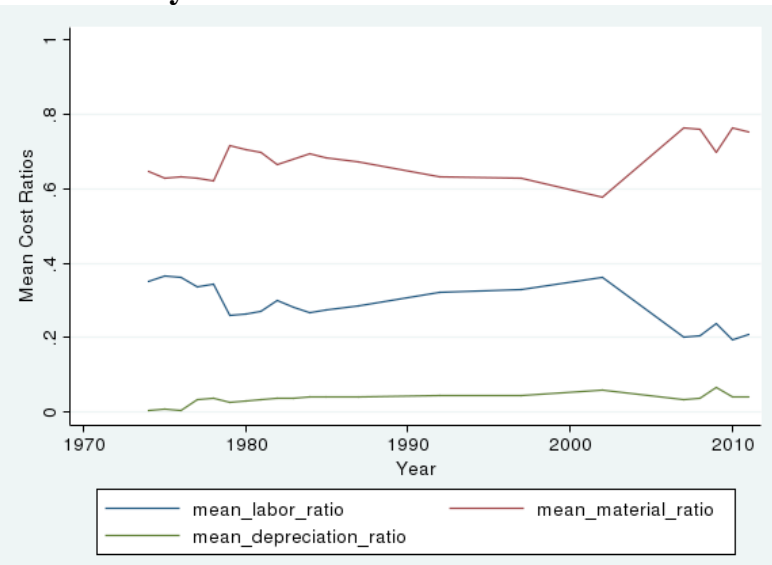




\section{Graph 4c: (cont'd)}
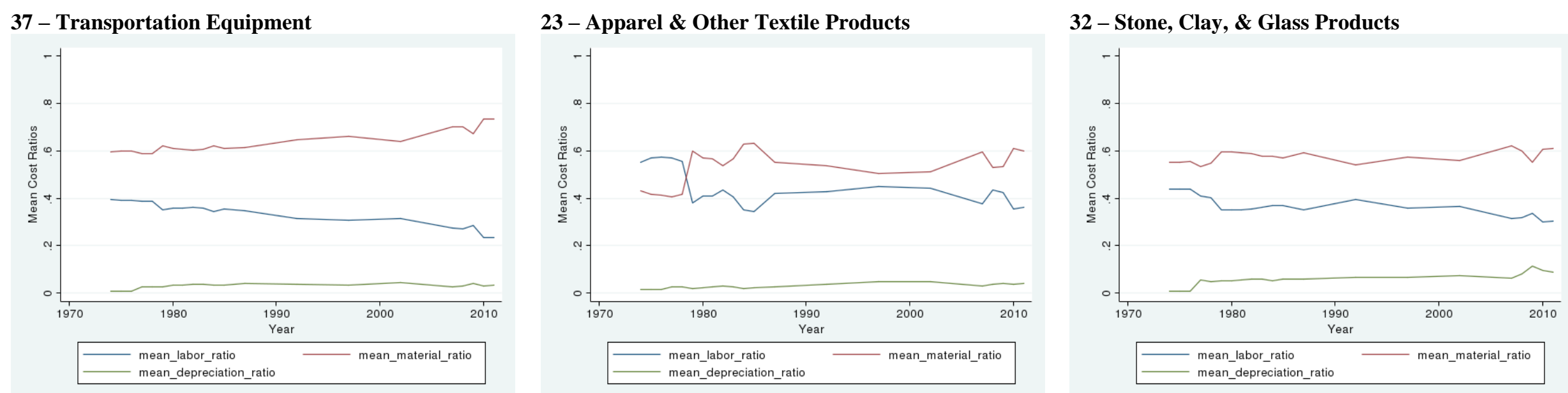

\section{4 - Lumber \& Wood Products}

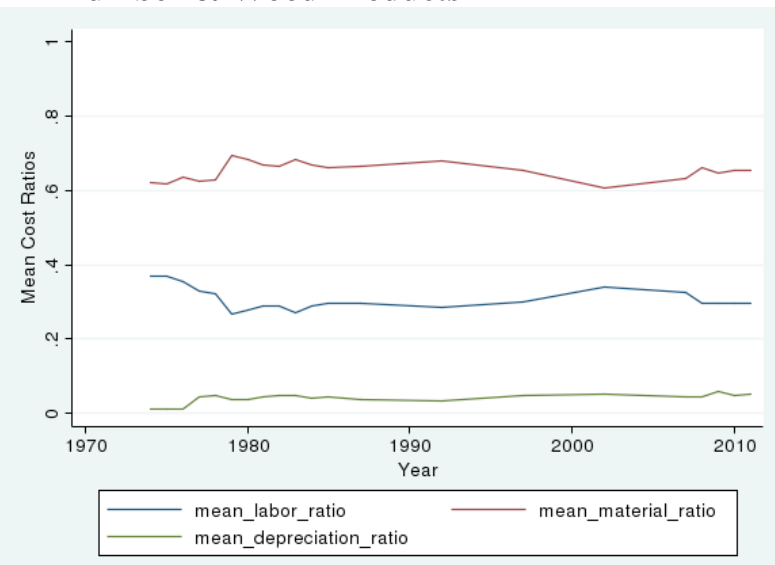

*Annual cross-sectional means of the proportions of the three cost components; $\mathrm{N}=110,500$ (rounded). See Appendix B for variable definitions. 
Graph 5: Ratio of estimates of establishment (i.e., plant) annual fixed costs to total costs over time

\section{Graph 5a: Full sample*}

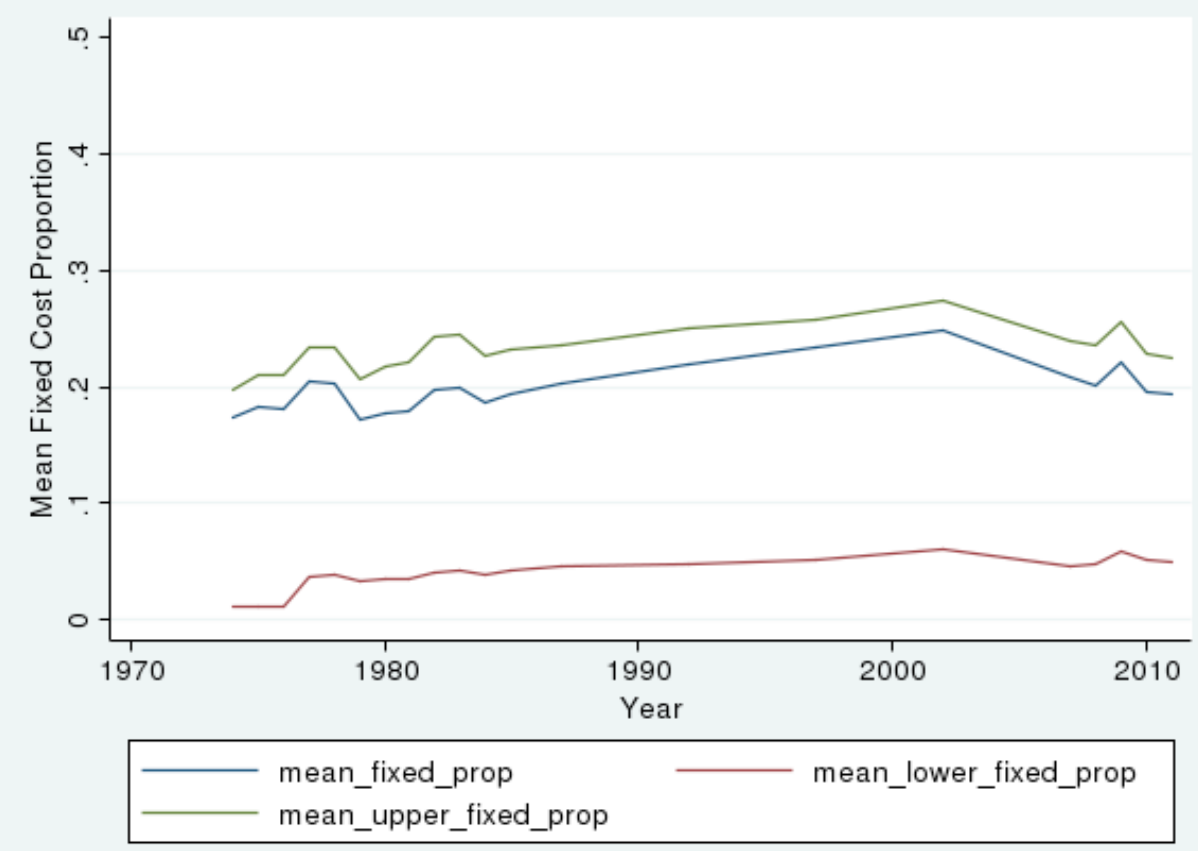

*Annual cross-sectional means of the proportions of fixed costs; $N=151,900$ (rounded). See Appendix B for variable definitions. 


\section{Graph 5b: Ratio of estimates of fixed costs to total costs over time in 2-digit industries*}

35 - Industrial Machinery \& Equipment

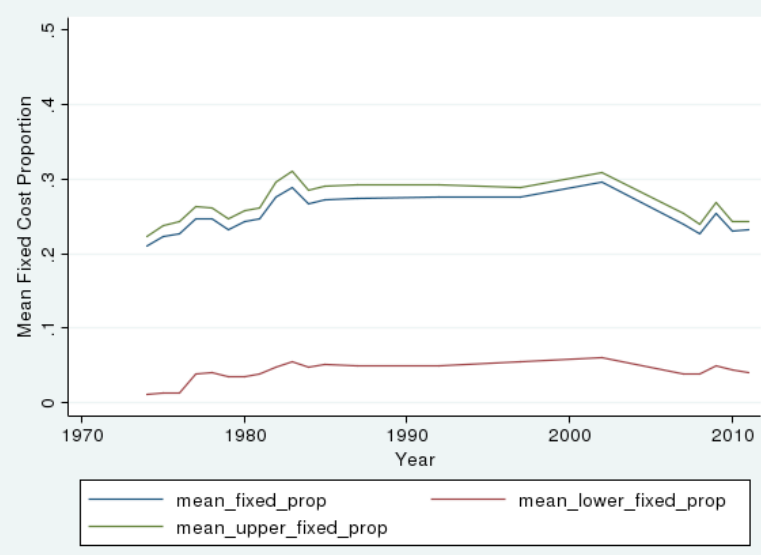

36 - Electronic \& Other Electric Equipment

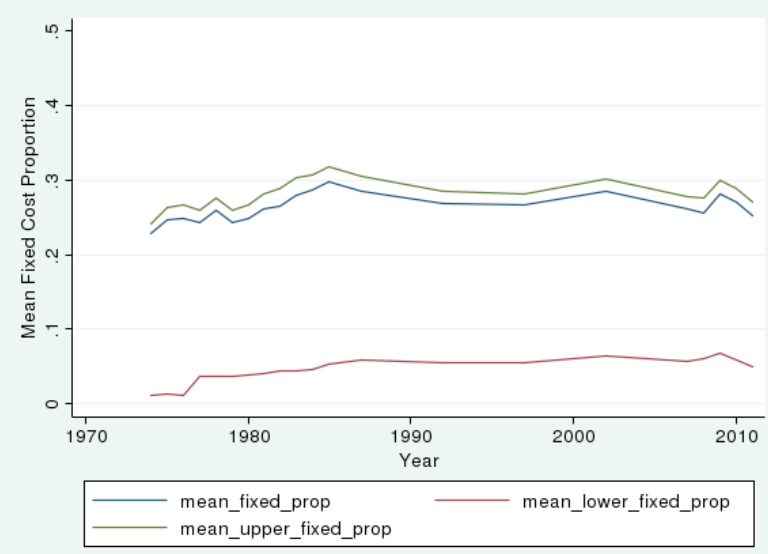

20 - Food \& Kindred Products

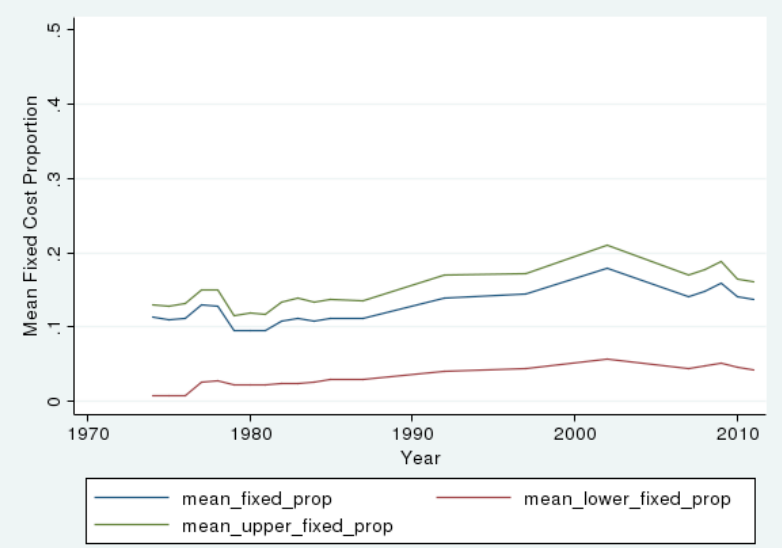

28 - Chemicals \& Allied Products

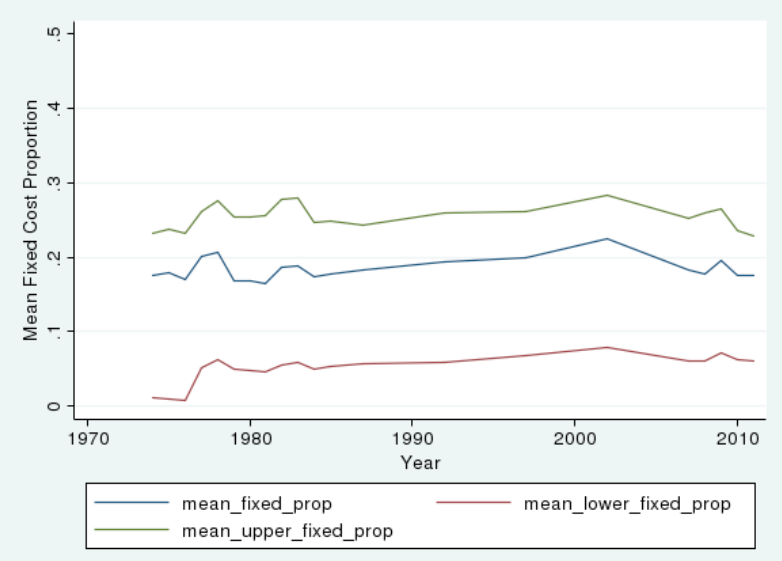

34 - Fabricated Metal Products

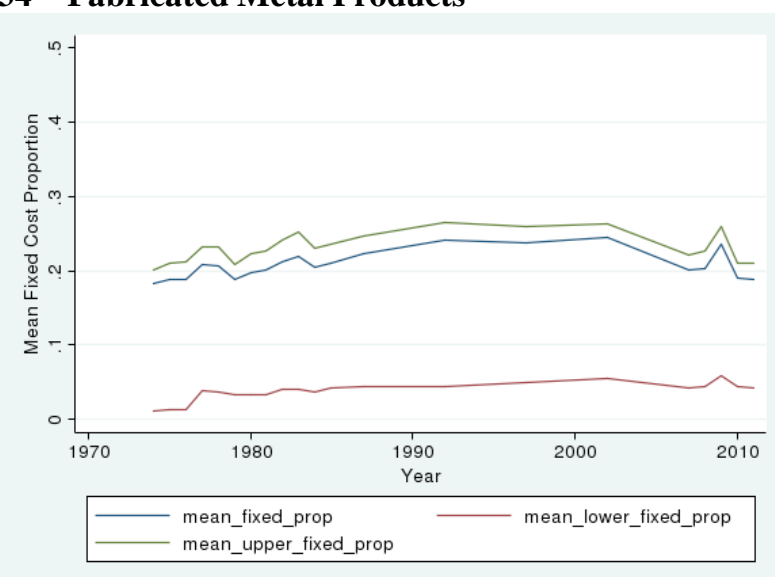

33 - Primary Metal Industries

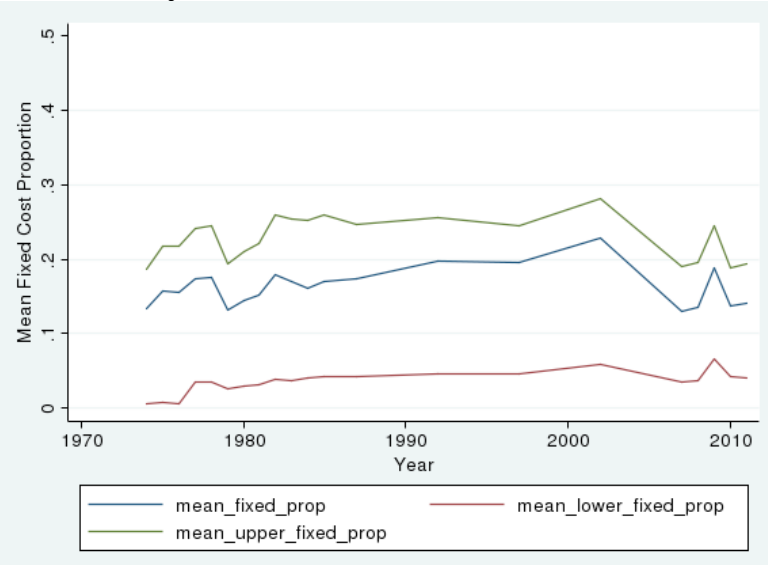


Graph 5b: (cont'd)
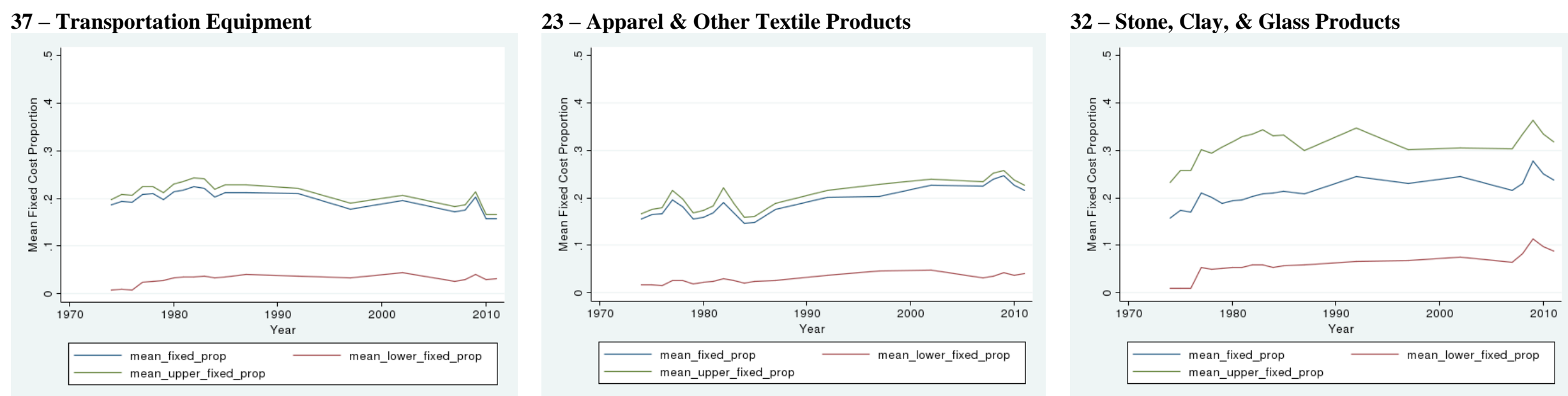

\section{4 - Lumber \& Wood Products}

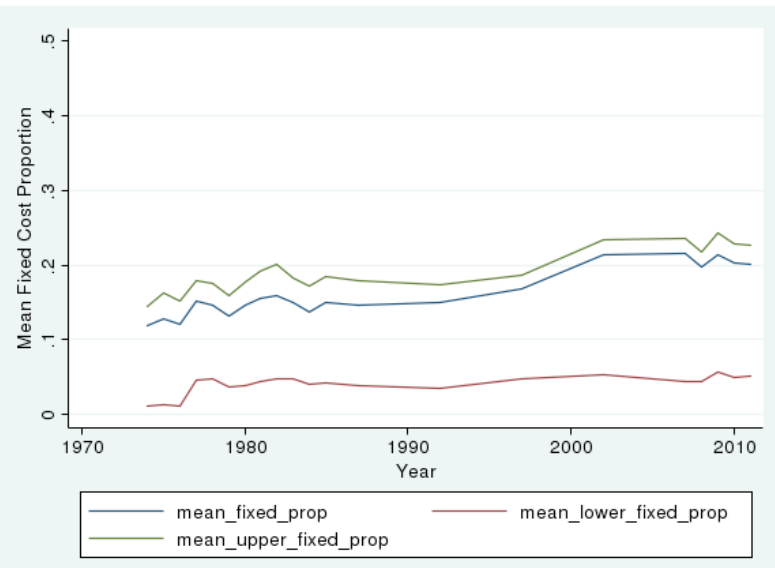

*Annual cross-sectional means of the proportions of fixed costs; $N=110,500$ (rounded). See Appendix B for variable definitions. 
Graph 6: Adjusted annual product costs relative to full costs after removing various estimates of costs of unused capacity at the establishment (i.e., plant) level

Graph 6a: Full sample*

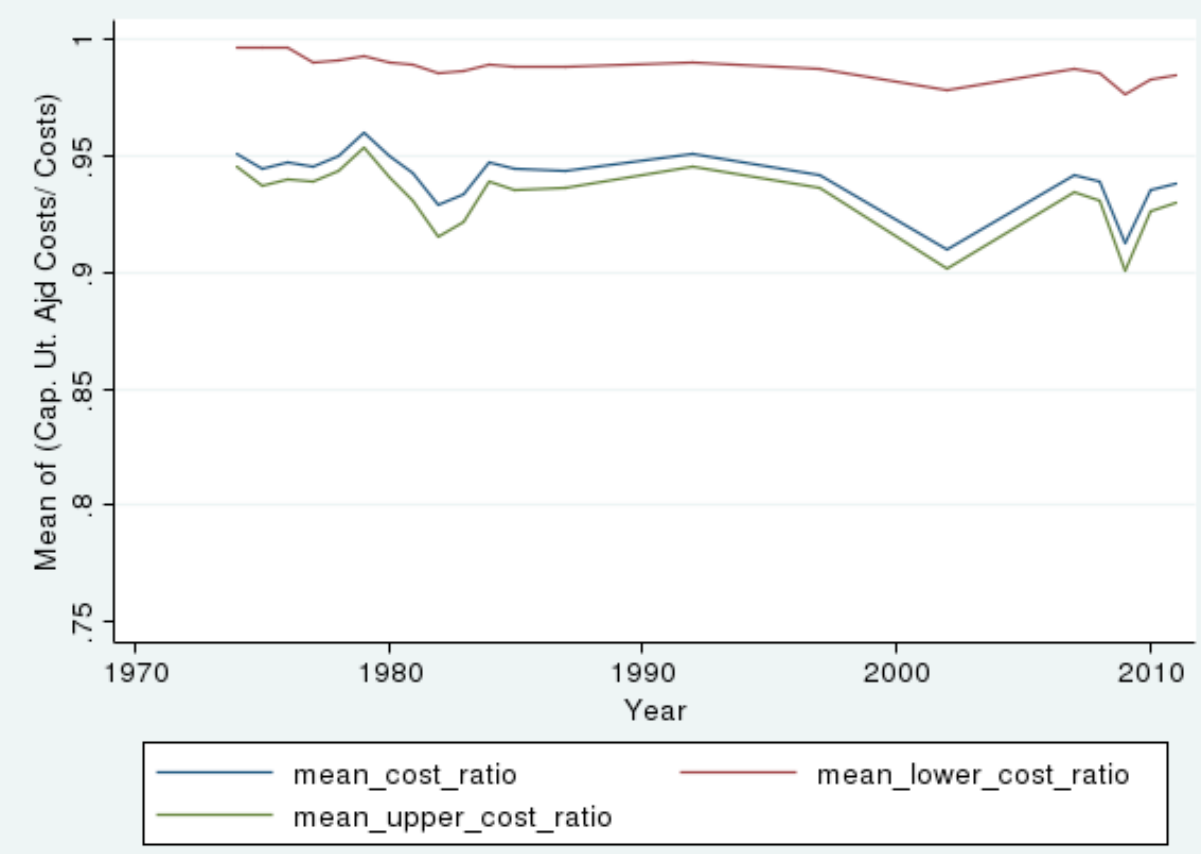

*Annual cross-sectional means of impact on costs; $N=151,900$ (rounded). See Appendix B for variable definitions. 
Graph 6b: Adjusted product costs relative to full costs after removing various estimates of costs of unused capacity in 2-digit industries ${ }^{*}$

35 - Industrial Machinery \& Equipment

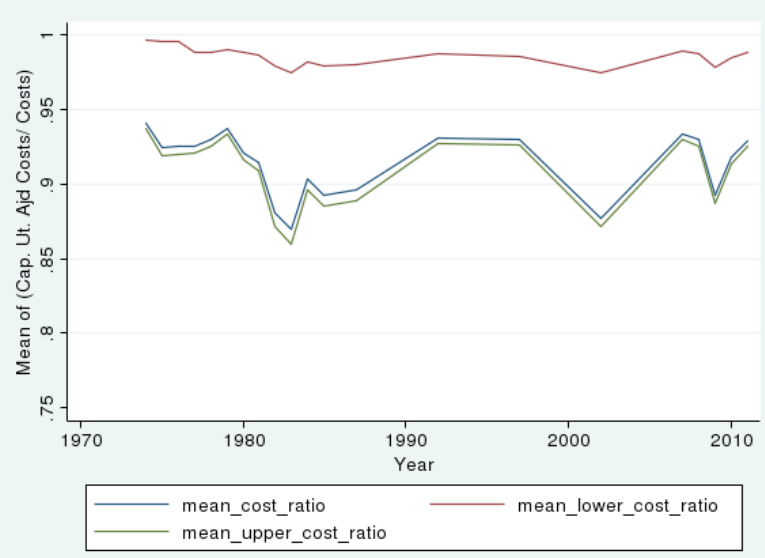

\section{6 - Electronic \& Other Electric Equipment}

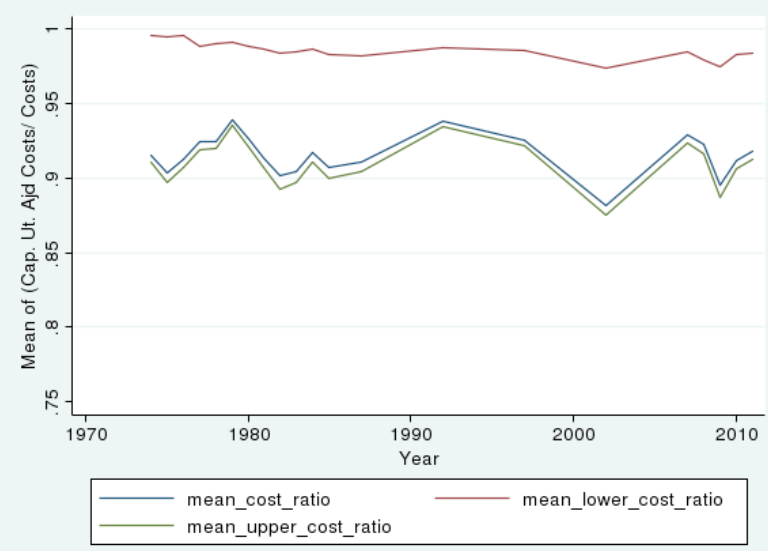

\section{0 - Food \& Kindred Products}

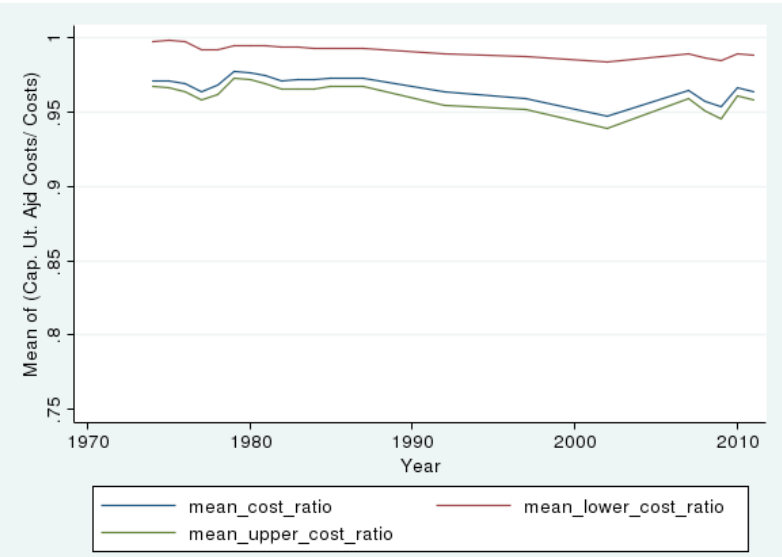

\section{8 - Chemicals \& Allied Products}

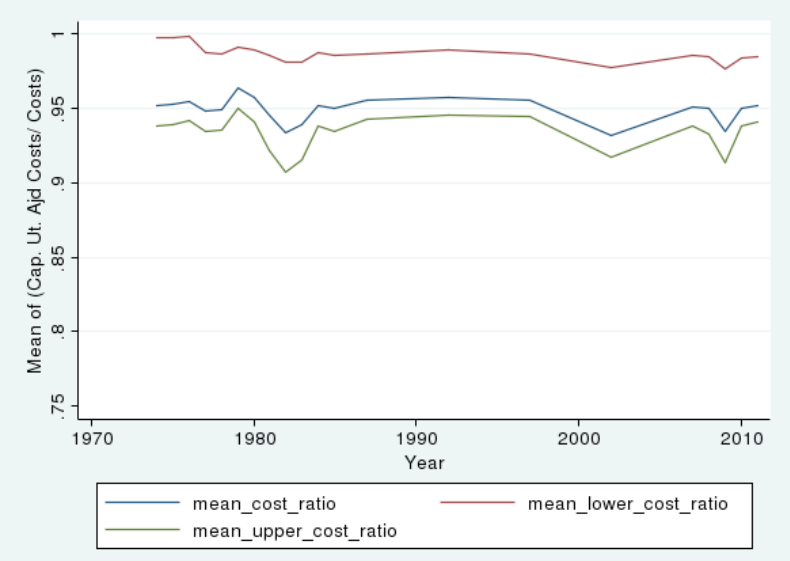

34 - Fabricated Metal Products

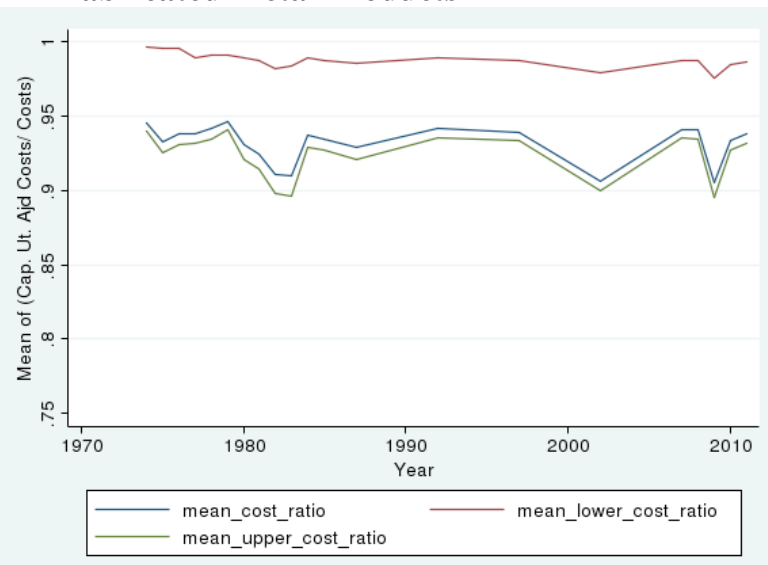

33 - Primary Metal Industries

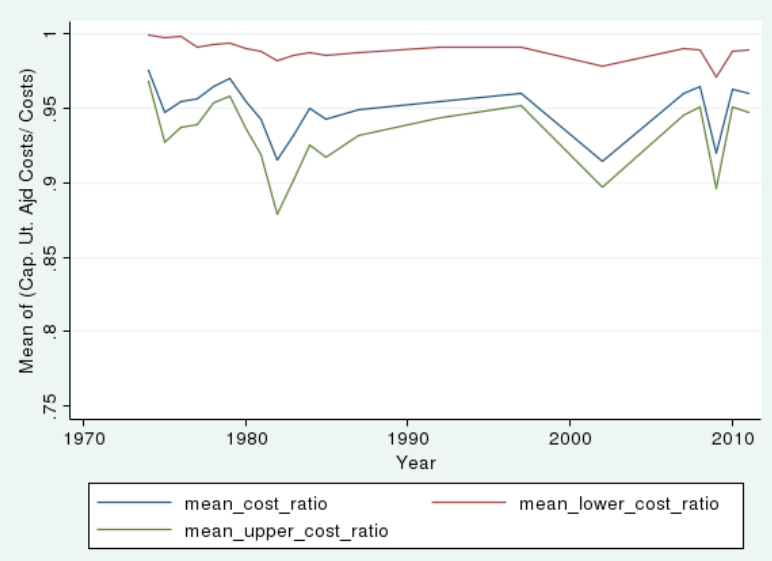


Graph 6b: (cont'd)

37 - Transportation Equipment

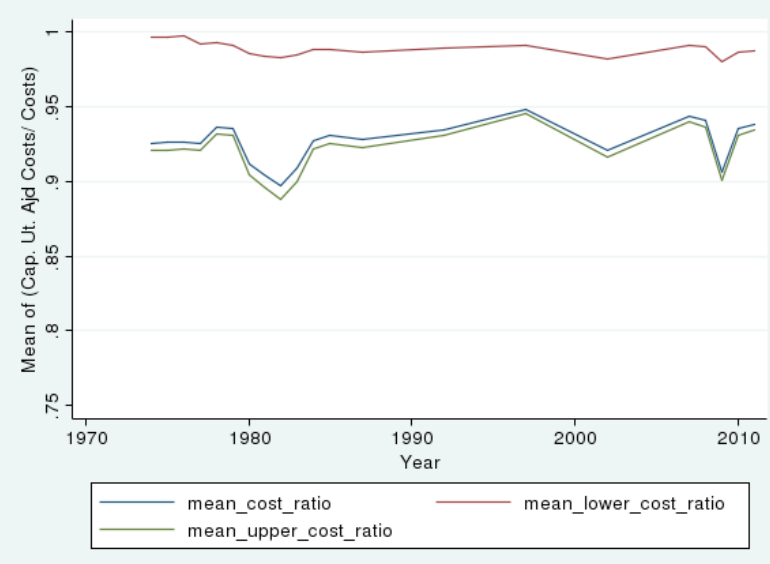

\section{3 - Apparel \& Other Textile Products}

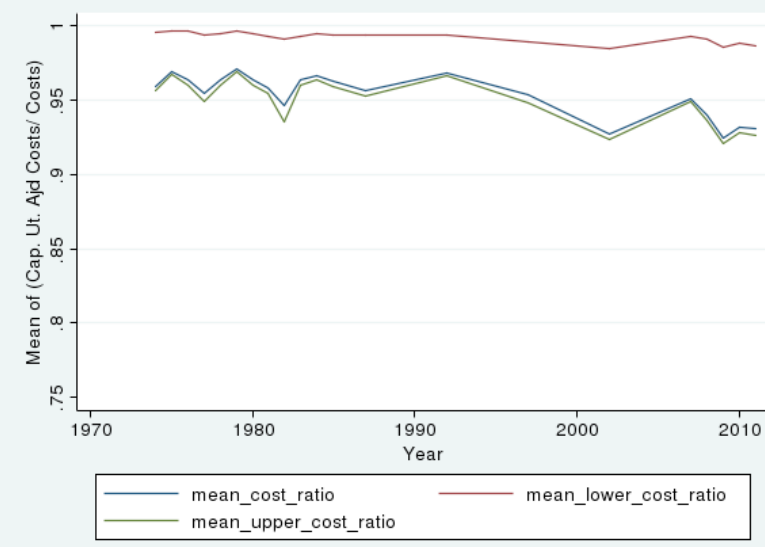

32 - Stone, Clay, \& Glass Products

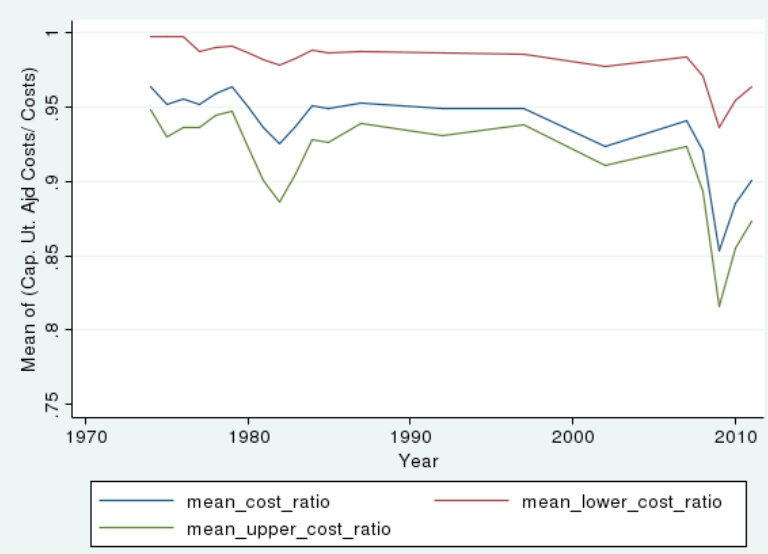

\section{4 - Lumber \& Wood Products}

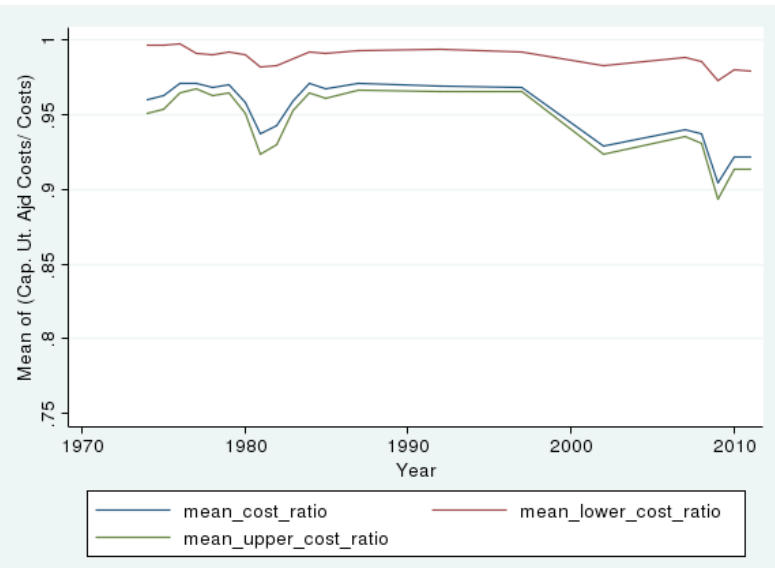

* Annual cross-sectional means of impact on costs; $N=110,500$ (rounded). See Appendix B for variable definitions. 
Graph 7: Annual profit margins using full costs and adjusted product costs from Graph 6 at the establishment (i.e., plant) level

\section{Graph 7a: Full sample*}

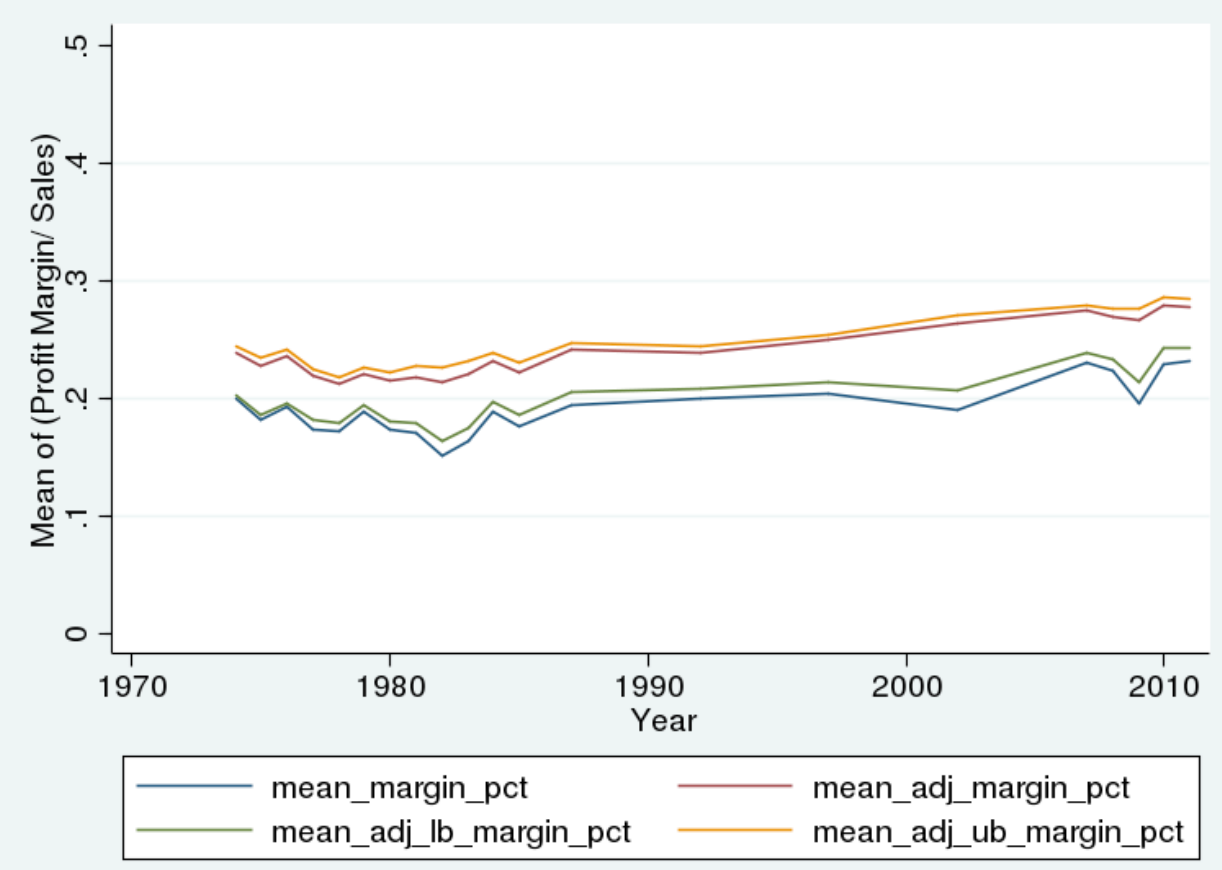

*Annual cross-sectional means of impact on profit margins; $N=151,900$ (rounded). See Appendix B for variable definitions. 


\section{Graph 7b: Profit margins using full costs and adjusted product costs from Graph 6 for 2-digit industries ${ }^{*}$}

35 - Industrial Machinery \& Equipment

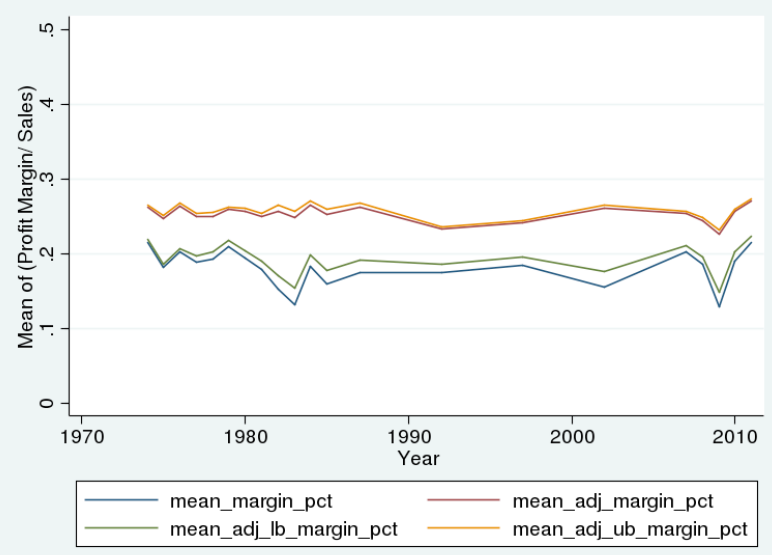

36 - Electronic \& Other Electric Equipment

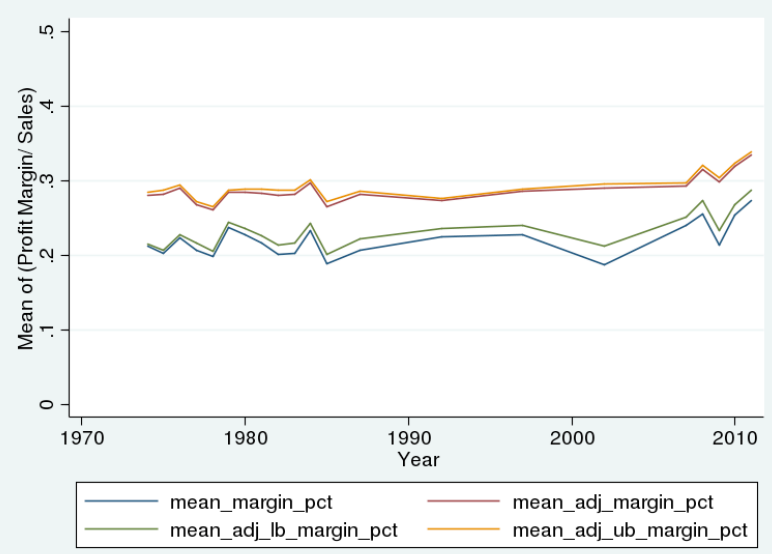

\section{0 - Food \& Kindred Products}

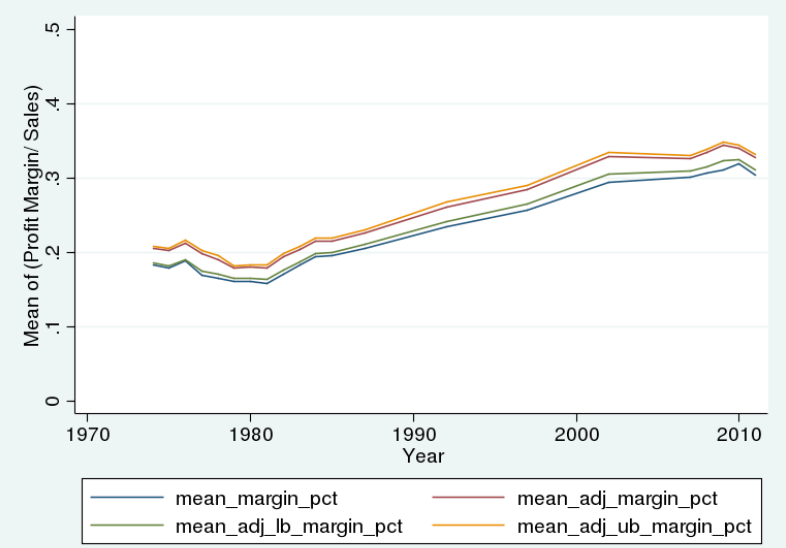

28 - Chemicals \& Allied Products

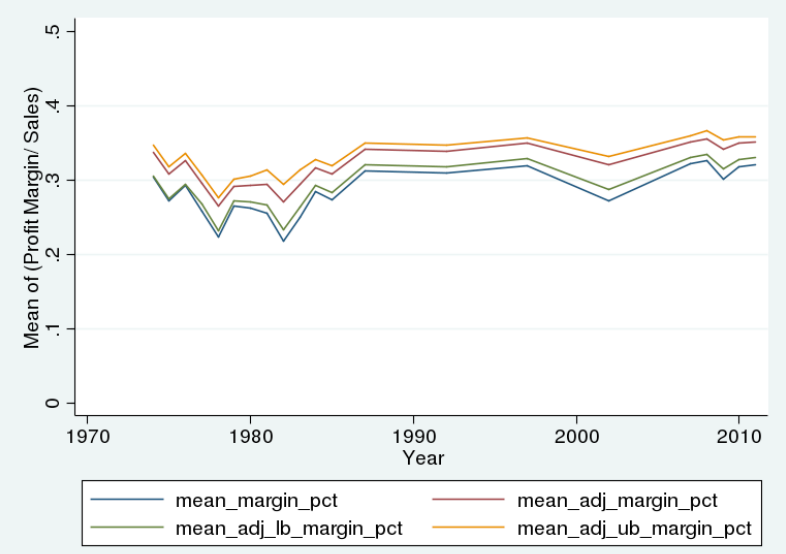

34 - Fabricated Metal Products

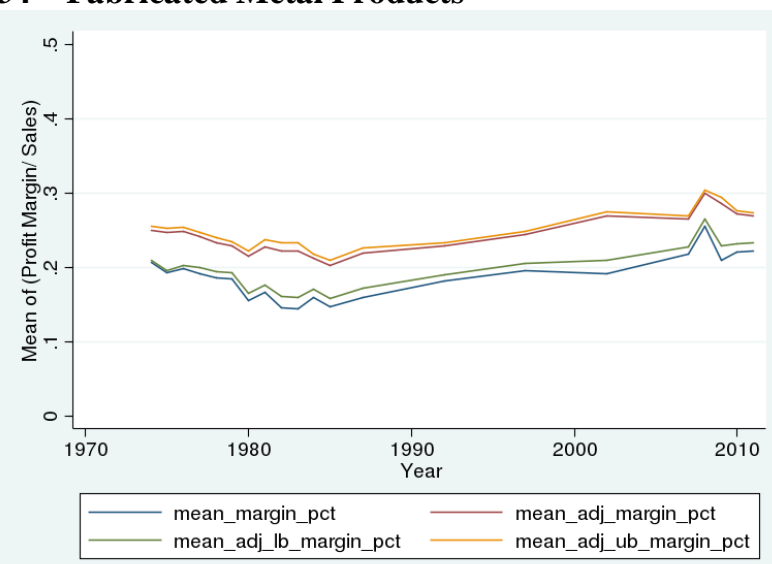

33 - Primary Metal Industries

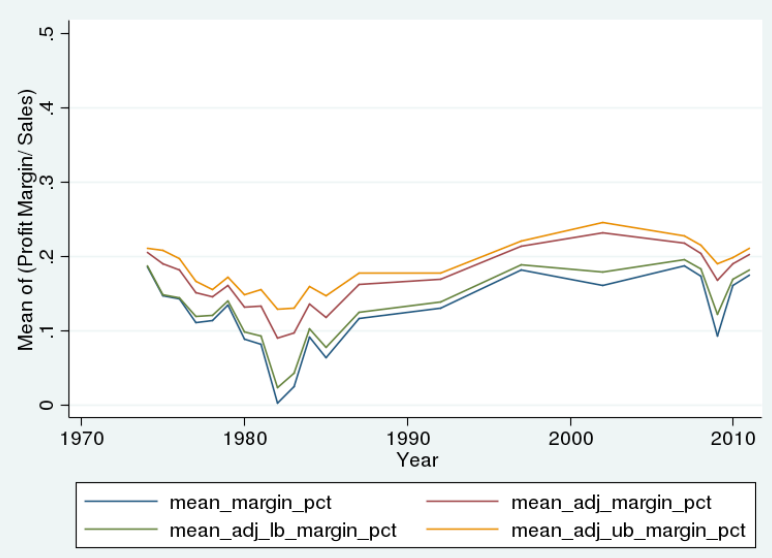




\section{Graph 7b: (cont'd)}
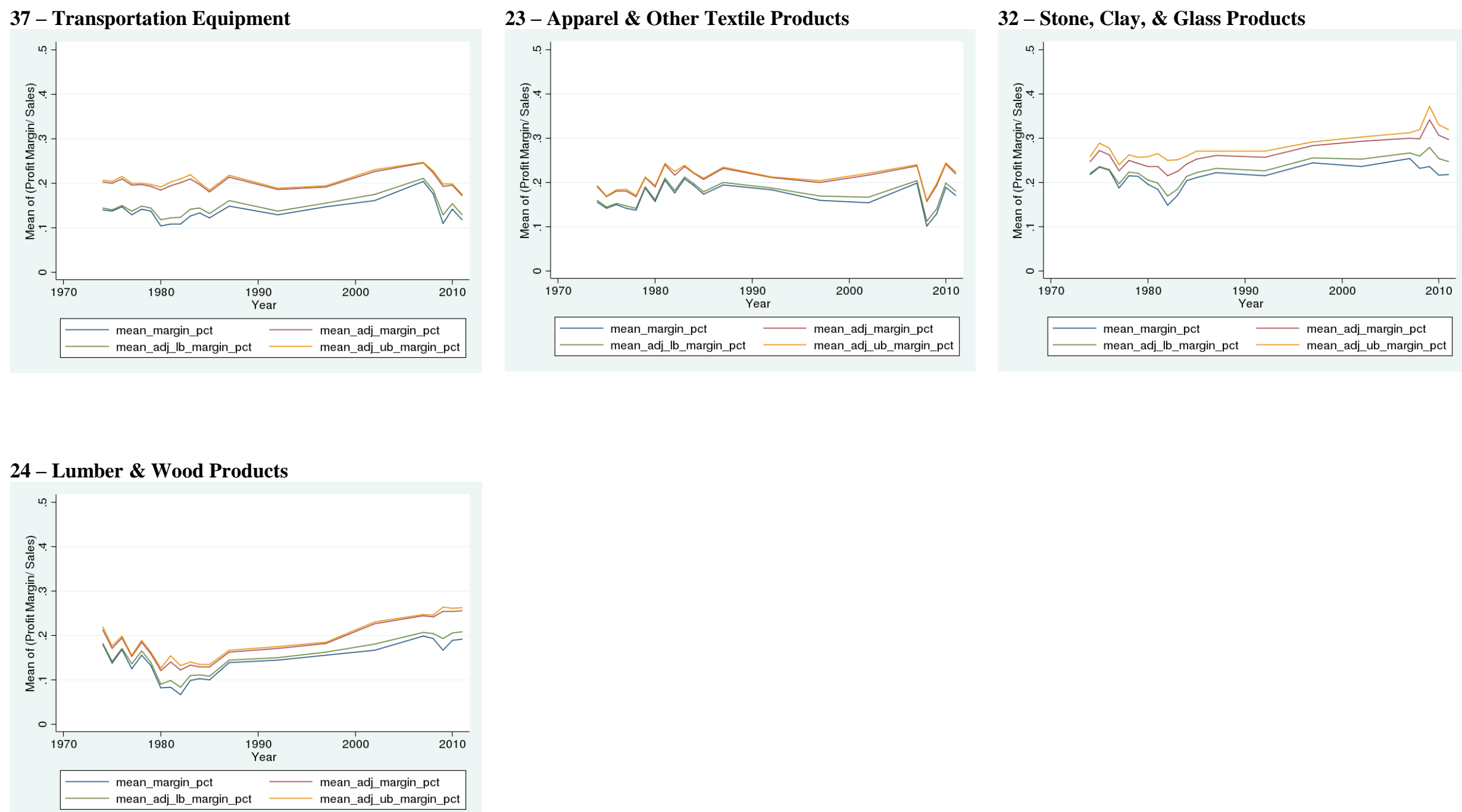

*Annual cross-sectional means of impact on profit margins; $N=110,500$ (rounded). See Appendix B for variable definitions. 
Graph 8: Plots of (sales - cogs)/sales [top plot] and net income/sales [bottom plot] for all COMPUSTAT firms in the 2-digit SIC codes in Table 2 for the years in Table 1*

Graph 8a: Sample of Compustat firms in all the 2-digit SIC codes in Table 2

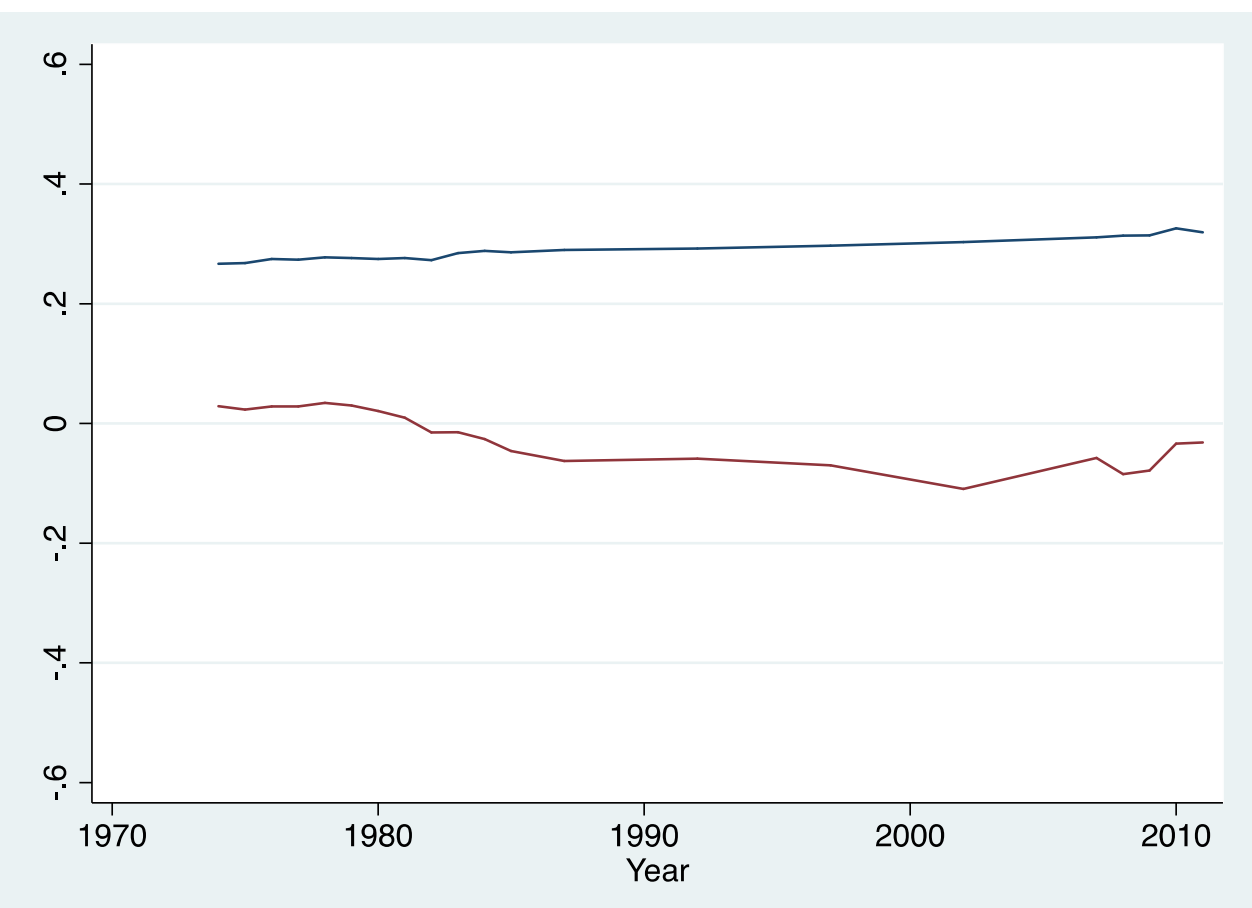

*Both ratios are winsorized at $5 \%$ and $95 \%$. 
Graph 8b: Sample of Compustat firms in each 2-digit SIC codes in Table 2

35 - Industrial Machinery \& Equipment

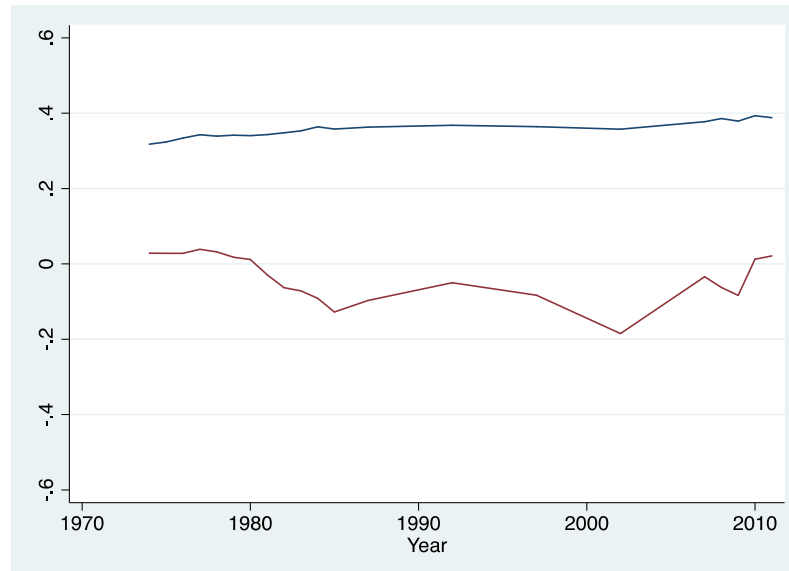

36 - Electronic \& Other Electric Equipment

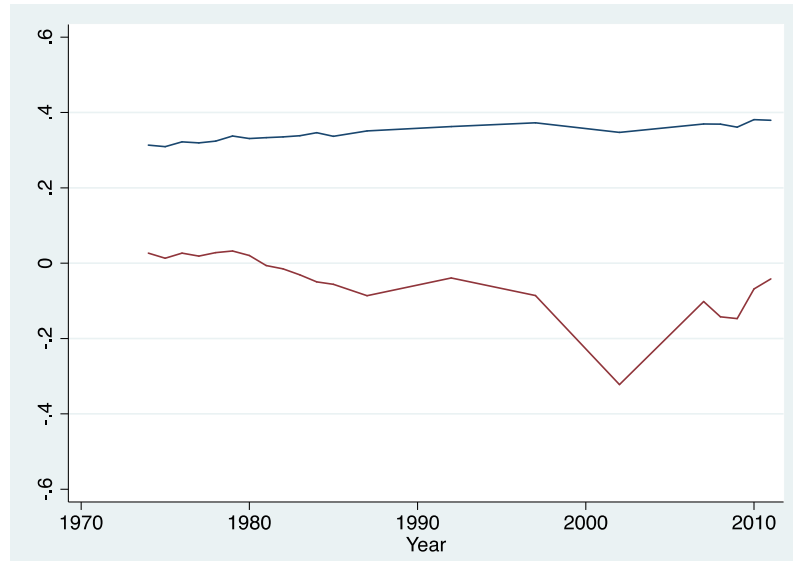

20 - Food \& Kindred Products

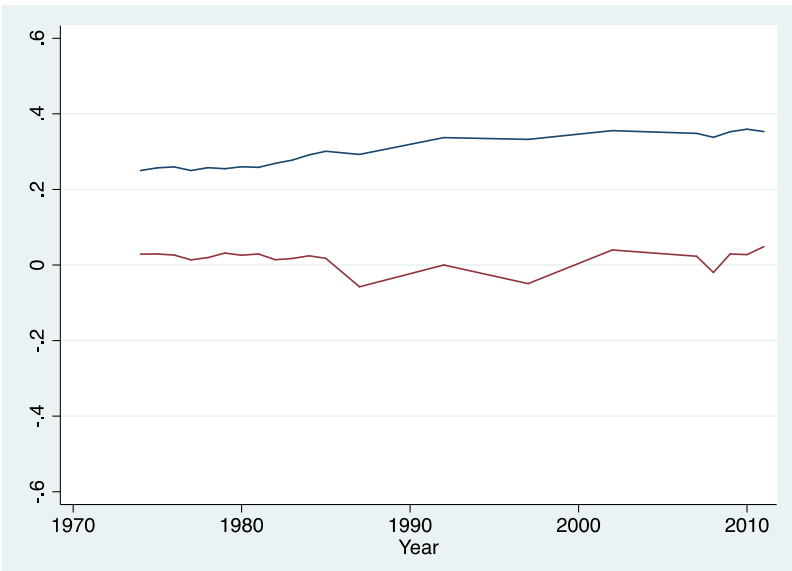

28 - Chemicals \& Allied Products

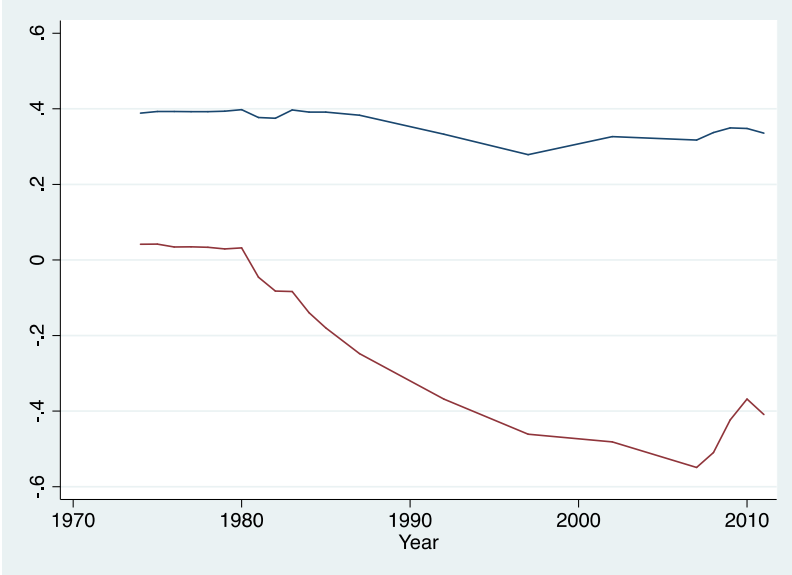

34 - Fabricated Metal Products

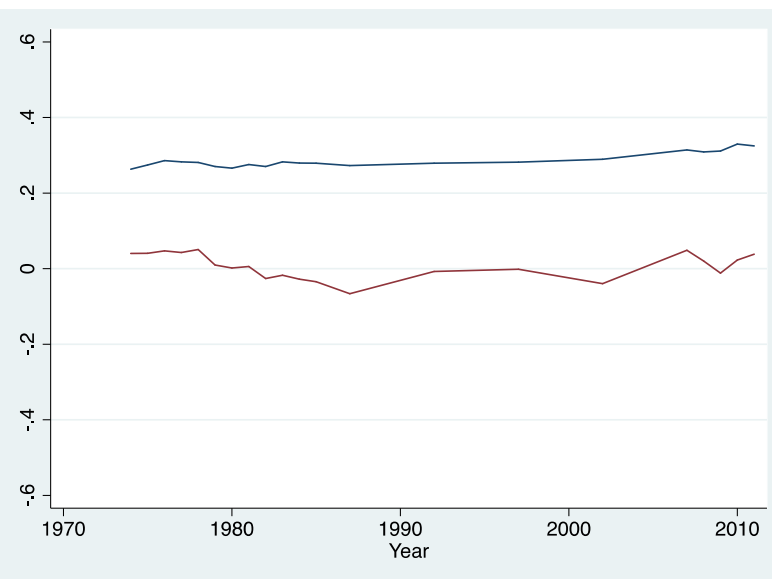

33 - Primary Metal Industries

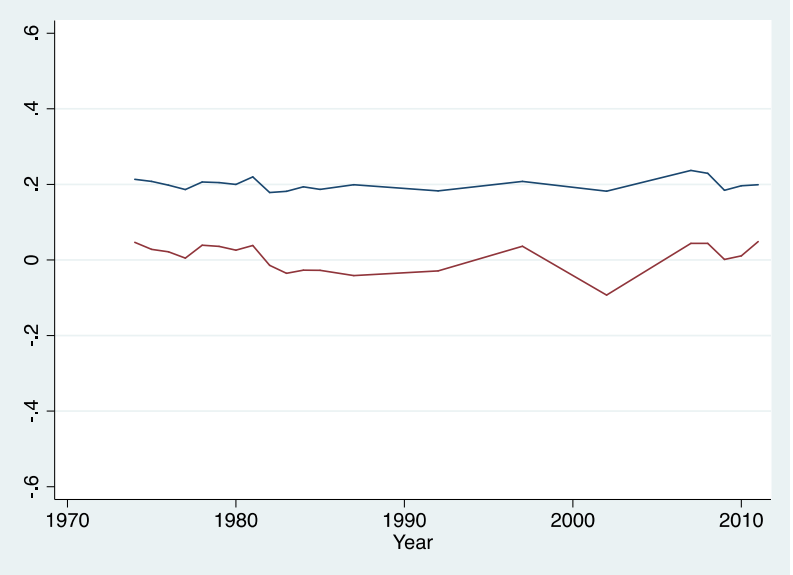


37 - Transportation Equipment

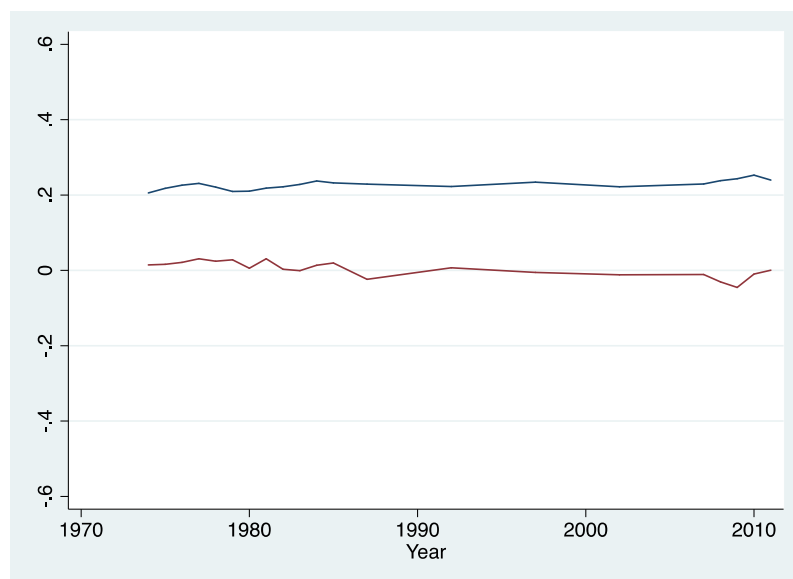

24 - Lumber \& Wood Products

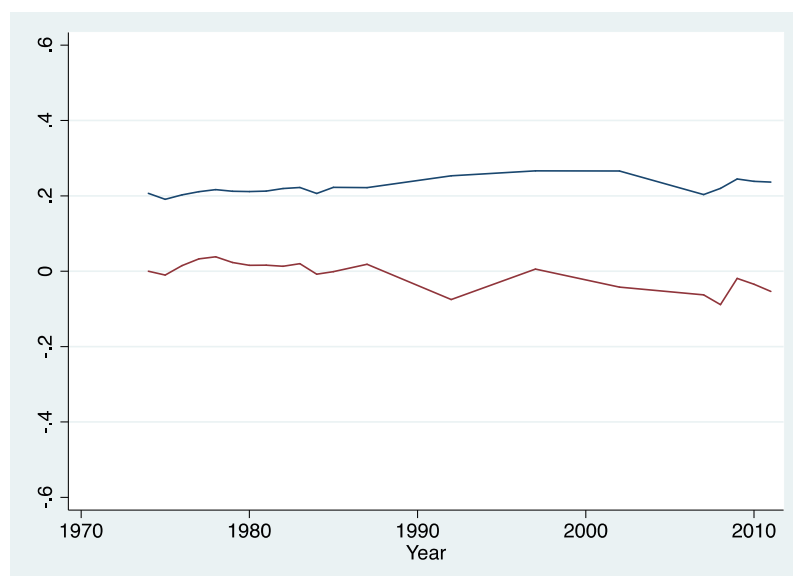

\section{Graph 8b: (cont'd)}

23 - Apparel \& Other Textile Products

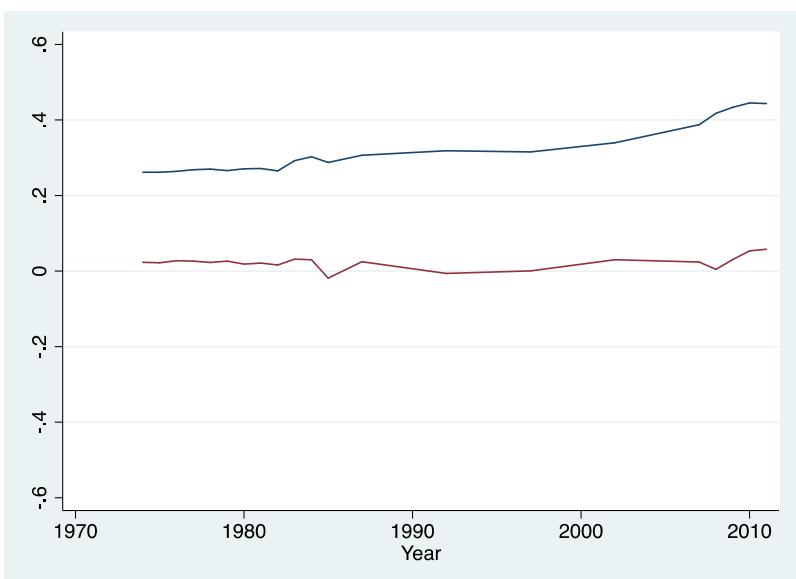

32 - Stone, Clay, \& Glass Products

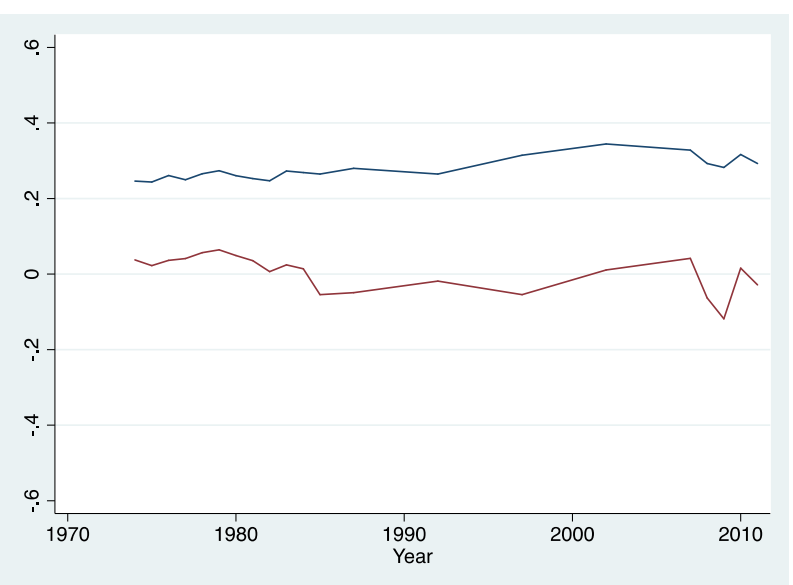


Table 3: Impact of capacity utilization on the relation between total output and capital, labor, and materials input for the annual establishment-level sample in Table 1

\begin{tabular}{|c|c|c|c|}
\hline & Model I & Model II & Model III \\
\hline Dependent variable $\rightarrow$ & $\log (\mathrm{Q})$ & $\log (\mathrm{Q})$ & $\log (\mathrm{Q})$ \\
\hline \multicolumn{4}{|l|}{$\underline{\text { Regressors }}$} \\
\hline $\begin{array}{l}\text { Capacity Utilization } \\
\text { (cap_ut) }\end{array}$ & & $\begin{array}{l}0.171^{* * *} \\
(19.21)\end{array}$ & $\begin{array}{c}0.233 * * * \\
(4.31)\end{array}$ \\
\hline $\log ($ KSTEQ $)$ & $\begin{array}{c}0.073 * * * \\
(15.59)\end{array}$ & $\begin{array}{c}0.076 * * * \\
(16.26)\end{array}$ & $\begin{array}{l}0.055^{* * *} \\
(7.73)\end{array}$ \\
\hline $\log ($ KSTEQ $) *$ cap_ut & & & $\begin{array}{c}0.029 * * * \\
(3.70)\end{array}$ \\
\hline $\log ($ KSTST $)$ & $\begin{array}{c}0.038 * * * \\
(11.10)\end{array}$ & $\begin{array}{c}0.041 * * * \\
(12.14)\end{array}$ & $\begin{array}{c}0.025^{* * * *} \\
(5.32)\end{array}$ \\
\hline $\log ($ KSTST $) *$ cap_ut & & & $\begin{array}{c}0.022 * * * \\
(4.12)\end{array}$ \\
\hline $\log (\mathrm{TH})$ & $\begin{array}{c}0.267 * * * \\
(25.79)\end{array}$ & $\begin{array}{c}0.262 * * * \\
(25.59)\end{array}$ & $\begin{array}{c}0.280 * * * \\
(20.25)\end{array}$ \\
\hline $\log (\mathrm{TH}) *$ cap_ut & & & $\begin{array}{c}-0.024 * * \\
(-2.27)\end{array}$ \\
\hline $\log (M)$ & $\begin{array}{c}0.498 * * * \\
(49.29)\end{array}$ & $\begin{array}{c}0.494 * * * \\
(49.13)\end{array}$ & $\begin{array}{c}0.524 * * * \\
(44.45)\end{array}$ \\
\hline $\log (\mathrm{M}) *$ cap_ut & & & $\begin{array}{c}-0.041 * * * \\
(-3.35)\end{array}$ \\
\hline $\log (E)$ & $\begin{array}{c}0.108 * * * \\
(17.58)\end{array}$ & $\begin{array}{c}0.106 * * * \\
(17.71)\end{array}$ & $\begin{array}{c}0.101 * * * \\
(15.79)\end{array}$ \\
\hline $\log (\mathrm{E}) *$ cap_ut & & & $\begin{array}{l}0.006 \\
(0.73)\end{array}$ \\
\hline $\mathrm{N}$ & 260,200 & 260,200 & 260,200 \\
\hline $\begin{array}{l}\text { Establishment SIC fixed } \\
\text { effects }\end{array}$ & 62,400 & 62,400 & 62,400 \\
\hline Year dummies & included & included & Included \\
\hline $\mathrm{R}^{2}$ & $91.77 \%$ & $91.80 \%$ & $91.81 \%$ \\
\hline
\end{tabular}


Unit of observation is annual establishment-level data from the TFP census databases ('asm[year]tfpb1' for years: 1974, 1975, 1976, 1978, 1979, 1980, 1981, 1983, 1984, 1985, 1986, 1988 1989, 1990, 1991, 1993, 1994, 1995, 1996, 1998, 1999, 2000, 2001, 2003, 2004, 2005, 2006, 2008, 2009, 2010. And 'cm[year]tfpb1' for years: 1977, $1982,1987,1992,1997,2002,2007)$ which have been especially constructed by the economics census researchers to compute total factor productivity of plants (see Foster et al. 2014 for details).

Variable definitions are: Q: discounted total value of shipments + change in finished goods inventory + change in work-in-process inventory; KSTEQ: equipment capital use estimated using a perpetual inventory method (Berleman and Wesslhoft 2014); KSTST: use of capital stock related to structures estimated using the perpetual inventory method (Berleman and Wesslhoft 2014); TH: total hours of production and non-production workers; M: physical material costs deflated by an industry level deflator; E: energy costs deflated by an industry level deflator. Capacity utilization (cap_ut): see Appendix B. All inputs and outputs are measure in constant 1997 dollars. All variables are truncated at the $1^{\text {st }}$ and $99^{\text {th }}$ percentile. Fixed effects are at the level of SIC 2-digit and establishment combined. Tstatistics in parantheses. $* * *$ is significance at the $1 \%$ two-tailed level. Note the number of observations are different in the ASM_FTP database. 


\section{Appendix A: Comparison of this study to prior studies}

\begin{tabular}{|c|c|c|}
\hline This Study & Prior Literature & Comment \\
\hline Table 2 & $\begin{array}{l}\text { Bens et al. 2011, } \\
\text { Table } 1 \text { C, pg. } 428\end{array}$ & $\begin{array}{l}\text { They only use CM years (' } 87, \text { ' } 92, \text { '97). More } \\
\text { importantly, they do not examine capacity costs, but } \\
\text { are instead interested in segment disclosure. }\end{array}$ \\
\hline \multirow[t]{3}{*}{ Graph $2 \& 3$} & $\begin{array}{l}\text { Banker et al. } 1988, \\
\text { Table } 7, \text { pg. } 188\end{array}$ & $\begin{array}{l}\text { Their empirical analysis supports their theoretical } \\
\text { model of optimal capacity levels under uncertainty. } \\
\text { They use industry-level data, as opposed to } \\
\text { establishment level data. } \\
\text { Industry-level capacity utilization data obtained from } \\
\text { the Census (which collects the data via the PCU } \\
\text { Survey). Data is for } 1974 \text { to } 1984 ; 20 \text { two-digit SIC } \\
\text { code industries in SIC codes } 20-39 \text {. }\end{array}$ \\
\hline & $\begin{array}{l}\text { Anderson 1995, pg. } \\
370\end{array}$ & $\begin{array}{l}\text { This study analyses the the impact of product mix } \\
\text { heterogeneity on manufacturing overhead cost. } \\
\text { Capacity utilization of three plants used in the study - } \\
\text { the rates are in the ballpark of our numbers. }\end{array}$ \\
\hline & & $\begin{array}{l}\text { Capacity utilization data from three plants (located in } \\
\text { small towns in the southeastern United States) of a } \\
\text { leading U.S. textile manufacturer for 1986-1990. }\end{array}$ \\
\hline \multirow[t]{2}{*}{ Graph 4} & $\begin{array}{l}\text { Banker et al. 2013, } \\
\text { footnote } 16, \text { pg. } 115\end{array}$ & $\begin{array}{l}\text { This study analyzes the impact of the strength of } \\
\text { employment protection legislation on level of cost } \\
\text { stickiness. Proportion of labor costs in operating costs } \\
\text { - in the ballpark of our numbers. } \\
128,333 \text { firm-years for } 15,833 \text { publicly listed non- } \\
\text { financial firms in } 19 \text { OECD countries for } 1990-2008 \\
\text { obtained from Compustat (North America and Global) } \\
69 \% \text { of observations have information on labor costs } \\
\text { missing. }\end{array}$ \\
\hline & $\begin{array}{l}\text { Dierynck et al. 2012, } \\
\text { pg. } 1228\end{array}$ & $\begin{array}{l}\text { This study examines the relationship between zero- } \\
\text { earnings benchmark and the level of cost stickiness. } \\
\text { They calculate the ratio of labor costs/ sales - in the } \\
\text { ballpark of our numbers. } \\
\text { Sample of } 37,880 \text { firm-years for unlisted Belgian firms }\end{array}$ \\
\hline
\end{tabular}




\begin{tabular}{|c|c|c|}
\hline & $\begin{array}{l}\text { Foster and Gupta } \\
1990 ; \text { Banker et al. } \\
1995\end{array}$ & $\begin{array}{l}\text { obtained from the Bel-First database of Bureau Van } \\
\text { Dijk for year 1993-2006. } \\
\text { These studies examine overhead cost drivers. The two } \\
\text { papers divide costs into direct material, direct labor, } \\
\text { and manufacturing overhead } \\
\text { Foster and Gupta: Data for } 37 \text { plants of an electronics } \\
\text { company located in the continental U.S. for 1986. } \\
\text { Banker et al. 1995: Data for } 32 \text { manufacturing plants } \\
\text { from the electronics, machinery, and automobile } \\
\text { components industries. }\end{array}$ \\
\hline Graph 5 & $\begin{array}{l}\text { Brueggen et al. } 2011 \text {, } \\
\text { pg. } 92\end{array}$ & $\begin{array}{l}\text { This study analyses the drivers and effects of excess } \\
\text { production. Data are obtained via interviews of 'a Big } \\
\text { Three automaker'. }\end{array}$ \\
\hline Graph 7 & $\begin{array}{l}\text { Bens et al., 2011, } \\
\text { footnote Table 2, pg. } \\
434\end{array}$ & $\begin{array}{l}\text { They also calculate a measure of profit margin } \\
\text { percentage. }\end{array}$ \\
\hline
\end{tabular}




\section{Appendix B: Measures}

All data are annual at the establishment, i.e., plant level, and all dollar figures are converted to 1982 USD using the annual Producer Price Index for all commodities obtained from the Bureau of Labor Statistics.

\begin{tabular}{|c|c|c|c|}
\hline$\underline{\text { Variable Name }}$ & $\underline{\text { Definition }}$ & Data Sources & $\underline{\text { Notes }}$ \\
\hline $\begin{array}{l}\text { Inflation-adjusted Total } \\
\text { Value of Shipments }\end{array}$ & $\begin{array}{l}\text { Total value of shipments/ Annual Producer Price Index for all } \\
\text { commodities }\end{array}$ & $\begin{array}{l}\text { Total value of } \\
\text { shipments: ASM/ CM } \\
\text { Producer Price Index: } \\
\text { Bureau of Labor } \\
\text { Statistics }\end{array}$ & \\
\hline Capacity Utilization & $\begin{array}{l}\text { Value of actual production / Value of production at practical (or } \\
\text { full) capacity utilization }\end{array}$ & $\begin{array}{l}\text { PCU until 2002; QPC } \\
\text { thereafter }\end{array}$ & $\begin{array}{l}\text { We use the reported data when } \\
\text { they are reported annually; } \\
\text { when the data are reported } \\
\text { quarterly, we aggregate the data } \\
\text { to create an annual measure. } \\
\text { The precise wording of the } \\
\text { survey questions, definitions, } \\
\text { and instructions changes } \\
\text { slightly over the time period, } \\
\text { but effectively, in each year the } \\
\text { survey asks for the market } \\
\text { value of actual production and } \\
\text { the market value of production } \\
\text { at practical (or full) capacity } \\
\text { utilization. }\end{array}$ \\
\hline Labor Costs & $\begin{array}{l}\text { (Production workers' wages }+ \text { All other salaries and wages }+ \\
\text { Total employer's cost of fringe benefits (supplemental labor } \\
\text { costs)) }\end{array}$ & $\mathrm{ASM} / \mathrm{CM}$ & $\begin{array}{l}\text { The precise wording of the } \\
\text { survey items changes slightly } \\
\text { over the time period. }\end{array}$ \\
\hline Material Costs & $\begin{array}{l}\text { (Cost of materials, parts, components, containers, etc., used + } \\
\text { Cost of products bought and sold as such + Cost of fuels + Cost } \\
\text { of purchased electricity + Cost of contract work done for you } \\
\text { by others) }\end{array}$ & $\mathrm{ASM} / \mathrm{CM}$ & $\begin{array}{l}\text { The precise wording of the } \\
\text { survey items changes slightly } \\
\text { over the time period. }\end{array}$ \\
\hline Depreciation Costs & (Total depreciation charges for the year + Total rental & $\mathrm{ASM} / \mathrm{CM}$ & The precise wording of the \\
\hline
\end{tabular}




\begin{tabular}{|c|c|c|c|}
\hline & payments) & & $\begin{array}{l}\text { survey items changes slightly } \\
\text { over the time period. }\end{array}$ \\
\hline Total Costs & (Labor Costs + Material Costs + Depreciation Costs) & $\mathrm{ASM} / \mathrm{CM}$ & \\
\hline Labor Ratio & Labor Costs/ Total Costs & $\mathrm{ASM} / \mathrm{CM}$ & \\
\hline Material Ratio & Material Costs/ Total Costs & $\mathrm{ASM} / \mathrm{CM}$ & \\
\hline Depreciation Ratio & Depreciation Costs/ Total Costs & $\mathrm{ASM} / \mathrm{CM}$ & \\
\hline Fixed Costs & $\begin{array}{l}\text { (All other salaries and wages + Total employer's cost of fringe } \\
\text { benefits (supplemental labor costs) + Total depreciation } \\
\text { charges for the year + Total rental payments) }\end{array}$ & $\mathrm{ASM} / \mathrm{CM}$ & \\
\hline $\begin{array}{l}\text { Fixed Costs - lower } \\
\text { bound }\end{array}$ & $\begin{array}{l}\text { (Total depreciation charges for the year + Total rental } \\
\text { payments) }\end{array}$ & $\mathrm{ASM} / \mathrm{CM}$ & \\
\hline $\begin{array}{l}\text { Fixed Costs - upper } \\
\text { bound }\end{array}$ & $\begin{array}{l}\text { (All other salaries and wages + Total employer's cost of fringe } \\
\text { benefits (supplemental labor costs) + Cost of fuels + Cost of } \\
\text { purchased electricity + Total depreciation charges for the year } \\
+ \text { Total rental payments) }\end{array}$ & ASM/ CM & \\
\hline Fixed Cost Proportion & Fixed Costs/ Total Costs & $\mathrm{ASM} / \mathrm{CM}$ & \\
\hline $\begin{array}{l}\text { Fixed Cost Proportion - } \\
\text { lower bound }\end{array}$ & Fixed Costs - lower bound/ Total Costs & $\mathrm{ASM} / \mathrm{CM}$ & \\
\hline $\begin{array}{l}\text { Fixed Cost Proportion - } \\
\text { upper bound }\end{array}$ & Fixed Costs - upper bound/ Total Costs & $\mathrm{ASM} / \mathrm{CM}$ & \\
\hline Cost Ratio & $\begin{array}{l}((\text { Fixed Costs x Capacity Utilization })+(\text { Total Costs }- \text { Fixed } \\
\text { Costs })) / \text { Total Costs }\end{array}$ & $\begin{array}{l}\mathrm{ASM} / \mathrm{CM} \text { and PCU/ } \\
\mathrm{QPC}\end{array}$ & \\
\hline $\begin{array}{l}\text { Cost Ratio - lower } \\
\text { bound }\end{array}$ & $\begin{array}{l}((\text { Fixed Costs }- \text { lower bound x Capacity Utilization })+(\text { Total } \\
\text { Costs }- \text { Fixed Costs })) / \text { Total Costs }\end{array}$ & $\begin{array}{l}\mathrm{ASM} / \mathrm{CM} \text { and } \mathrm{PCU} / \\
\mathrm{QPC}\end{array}$ & \\
\hline $\begin{array}{l}\text { Cost Ratio - upper } \\
\text { bound }\end{array}$ & $\begin{array}{l}((\text { Fixed Costs }- \text { upper bound x Capacity Utilization })+(\text { Total } \\
\text { Costs }- \text { Fixed Costs })) / \text { Total Costs }\end{array}$ & $\begin{array}{l}\mathrm{ASM} / \mathrm{CM} \text { and } \mathrm{PCU} / \\
\mathrm{QPC}\end{array}$ & \\
\hline Productive Output & $\begin{array}{l}\text { (Total Value of Shipments + (Value of Finished Goods } \\
\text { Inventory at End of Year - Value of Finished Goods Inventory } \\
\text { at Beginning of Year + Value of Work-in-Process Inventory at } \\
\text { End of Year - Value of Work-in Process Inventory at } \\
\text { Beginning of Year) }\end{array}$ & $\mathrm{ASM} / \mathrm{CM}$ & \\
\hline Margin & (Productive Output - Total Costs)/ (Productive Output) & $\mathrm{ASM} / \mathrm{CM}$ & $\begin{array}{l}\text { This variable is winsorized at } \\
\text { the } 1^{\text {st }} \text { and the } 99^{\text {th }} \text { percentile }\end{array}$ \\
\hline Adjusted Margin & $\begin{array}{l}\text { (Productive Output }-(\text { Total Costs - Fixed Costs + Fixed Costs } \\
* \text { Capacity Utilization) }) /(\text { Productive Output) }\end{array}$ & $\begin{array}{l}\mathrm{ASM} / \mathrm{CM} \text { and PCU/ } \\
\mathrm{QPC}\end{array}$ & $\begin{array}{l}\text { This variable is winsorized at } \\
\text { the } 1^{\text {st }} \text { and the } 99^{\text {th }} \text { percentile }\end{array}$ \\
\hline Adjusted Margin - lower & (Productive Output $-($ Total Costs - Fixed Costs Lower Bound & $\mathrm{ASM} / \mathrm{CM}$ and $\mathrm{PCU} /$ & This variable is winsorized at \\
\hline
\end{tabular}




\begin{tabular}{|l|l|l|l|}
\hline bound & $\begin{array}{l}\text { + Fixed Costs Lower Bound * Capacity Utilization)/ } \\
\text { (Productive Output) }\end{array}$ & QPC & the $1^{\text {st }}$ and the 99 $9^{\text {th }}$ percentile \\
\hline $\begin{array}{l}\text { Adjusted Margin - } \\
\text { upper bound }\end{array}$ & $\begin{array}{l}\text { (Productive Output) - (Total Costs - Fixed Costs Upper Bound } \\
\text { + Fixed Costs Upper Bound * Capacity Utilization)/ } \\
\text { (Productive Output) }\end{array}$ & $\begin{array}{l}\text { ASM/ CM and PCU/ } \\
\text { QPC }\end{array}$ & $\begin{array}{l}\text { This variable is winsorized at } \\
\text { the } 1^{\text {st }} \text { and the } 99^{\text {th }} \text { percentile }\end{array}$ \\
\hline
\end{tabular}

$*$ The detailed coding procedures are available from the authors upon request. 